\title{
UK IPOs: Long Run Returns, Behavioural Timing and Pseudo Timing
}

\author{
Alan Gregory \\ University of Exeter \\ Cherif Guermat \\ University of West of England \\ Fawaz Al-Shawawreh \\ University of Exeter \section{Discussion Paper no: 08/06} \\ Xfi - Centre for Finance and Investment
}

This Version: Sept 2009

\begin{abstract}
In this paper we examine a comprehensive set of 2,499 UK IPOs launched between mid-1975 and the end of 2004. We find compelling evidence of long run underperformance that persists for between 36 and 60 months post-flotation, depending on the precise method chosen to measure abnormal returns. Following Schultz (2003), we ask whether our results are consistent with "pseudo-timing". Equally-weighted returns in calendar time provide further evidence of under-performance, a result that favours the Loughran and Ritter (2000) behavioural timing hypothesis rather than the Schultz (2003) pseudo-timing hypothesis. However, we show that this underperformance is concentrated in AIM and USM stocks. When we measure valueweighted returns in calendar time we find that abnormal returns are not significantly different from zero. Further analysis shows that, consistent with the findings of other studies, IPO under-performance is concentrated in smaller firms.
\end{abstract}

JEL Classifications: G14; G32

All errors remain the responsibility of the authors 


\section{UK IPOs: Long Run Returns, Behavioural Timing and Pseudo Timing}

\section{Introduction}

Recently, US evidence on the under-performance of Initial Public Offerings (IPOs) (Ritter, 1991; Loughran and Ritter, 1995, 2000) has been challenged on two counts. First, the validity of the assumptions inherent in event time methodologies (e.g. Mitchell and Stafford, 2000) has been questioned. This is important, as the evidence for the UK and elsewhere potentially seems to differ depending on whether calendar time methods or event time methods are used (e.g. Espenlaub et al., 2000). The second challenge comes from the "pseudo timing" hypothesis of Schultz (2003). Pseudo-timing is Schultz's term for the situation where managers of firms, believing markets are inefficient, react to market-wide pricing conditions by issuing equity (or launching an IPO) even though in reality market prices are efficient. This stands in marked contrast to the Loughran and Ritter (2000) hypothesis where market prices are assumed to be inefficient, a condition that is exploited by managers knowingly issuing over-valued equity. Under the Loughran and Ritter story, the observed underperformance of IPOs (and seasoned equity offerings, SEOs) is real and the result of managers successfully exploiting market mispricing. However, the Schultz version of events is entirely different. Here, managers merely observe market prices and adjust the supply of IPOs so that there are more offerings following price rises (and less following price falls). They have zero market timing ability. Using a simple simulation model, Schultz shows that under such conditions, an event time methodology falsely leads to a conclusion of market timing ability, because the number of events observed is not an exogenous variable, but rather one that depends on the level of the market in the first place. Thus, we will observe significant negative returns in event time, which will lead us to (falsely) conclude that managers have market timing ability. However, calendar time returns are not so affected, leading Schultz to prefer calendar time tests to event time tests. Schultz reports that the significant event-time negative returns for US IPOs become much closer to zero and insignificant when calculated on a calendar time basis. Support for the Schultz 
hypothesis can be found in Butler et al. (2005), but counter-evidence emerges in Baker et al. (2006) and Chan et al. (2007).

Approval of the calendar time approach is not universal. Loughran and Ritter (2000) argue that the use of value-weighted returns and calendar time returns will result in extremely weak tests if managers do, in fact, possess behavioural timing ability when making corporate financing decisions. Second, from a statistical testing viewpoint, whilst the use of calendar time portfolios is advocated by Mitchell and Stafford (2000) and by Fama (1998), who notes that it mitigates the effects of the "bad model" problem and also argues that most of the apparent anomalies found in the literature disappear or become less significant when abnormal returns are estimated in calendar time, the main disadvantage is that it does not reflect investor experience as well as the event-time approach. A recent paper by Liu and Strong (2008) warns against the general danger of drawing false inferences from market-based studies. Although that paper was concerned primarily with single month partitioning of longer period returns, the biases they discuss are implicit in the calendar time portfolio approach. Whether value-weighting or equal weighting is employed, the implied portfolio rebalancing inherent in a calendar time approach could give rise to the biases noted by the authors, and in addition result in portfolios which seem implausible from an investor point of view. Furthermore, both Fama (1998) and Mitchell and Stafford (2000) recognise that a potential problem with the calendar time approach is that changing the number of firms in the calendar time portfolio through time has the potential to create residual heteroscedasticity that can affect inferences about the coefficients. A further problem with a factor approach to calendar time portfolios is that the method imposes the requirement that the factor loadings are constant, even though the portfolio composition changes radically over the period of the study. Nonetheless, both Lyon et al. (1999) and Dichev and Piotroski (2001) recommend that buy-and-hold returns and calendar-time regressions ought to be considered as complements rather than substitutes. In this paper we follow that advice, and report both calendar time and event time returns. However, we employ new methods in the calendar time portfolios to take account of possible heteroscedasticity in portfolio returns. 
Our objectives in this research are several fold. First, in employing by far the most comprehensive data set of UK IPOs investigated to date, covering 2,499 IPOs floated on the London market between January 1975 and December 2004, we are able to lay to rest any hints that results from previous UK study may have been time period and sample specific. Results for the UK that broadly confirm the US findings outlined above are reported by Aggarwal and Rivoli (1990), Levis (1993) and Goergen, Khurshed and Mudambi (2007). These authors confirmed that underperformance of UK IPOs extend over 36 full months after the first day of issue. In particular Levis (1993) suggested that the long-term underperformance extends beyond the 36 months. ${ }^{1}$ Recent evidence on the UK is provided by Espenlaub, Gregory, and Tonks (2000). ${ }^{2}$ However, they point out that tests of underperformance may be sensitive to the choice of empirical method used to measure performance. Abnormal returns over a three year period after the offerings were significant and negative irrespective of the benchmark employed in their event-time approach, though over a five year period the underperformance was less dramatic and sensitive to the benchmark employed. This study plays an important role in extending the time period examined in these studies back to 1975 and forward to the end of 2004.

Second, in employing the BHAR methods of Lyon et al. (1999) with control portfolios calculated according to the principles set out in Liu and Strong (2008), we are able to calculate abnormal returns that could actually have been achieved by investors systematically buying new IPO issues. Despite the well-known problems of cumulated abnormal returns (CARs), we nonetheless note results from such a method for completeness. Third, we employ a more sophisticated bootstrapping approach to estimating the significance levels of the BHARs than the simple bootstrapping method of Lyon et al. (1999). Fourth, we directly examine the timing issue in order to test whether the data suggest any evidence of market timing, either "pseudo" or behavioural. Fifth, despite our reservations about the realism of abnormal returns derived from calendar time methods, by employing them we are able to shed light on whether managers of IPO firms appear to have genuine market timing ability, or

\footnotetext{
${ }^{1}$ Levis's (1993) results were based on a sample of 712 issues from 1980-1988.

${ }^{2}$ They use a sample of 588 UK IPO firms over the period 1985 to 1992 . Their study compares abnormal performance based on five alternative benchmarks using both event-time approach and calendar -time approach.
} 
whether they are exhibiting the characteristics associated with "pseudo-timing". Sixth, we separately analyse the performance of Main Market, Unlisted Securities Market (USM) and Alternative Investment Market (AIM) stocks. Last, we employ some innovative approaches to the problem of heteroscedasticity in calendar time portfolio returns.

The paper now proceeds as follows. The first section gives the usual description of data and research methods. The second section discusses the results obtained from event period returns analysis. The third section examines the timing issue, the fourth shows the results from calendar time approaches, and the final section examines the results according to size and market of listing effects.

\section{Data and research method}

\section{IPO data}

A comprehensive sample of UK IPOs from January 1975 to December 2004 was collected from the London Stock Database Price (LSPD), using the LSPD "birth marker" to identify the nature of the IPO. A total of 433 IPOs were then excluded from the sample because they are identified as investment trusts, finance companies, or banks, leaving a final sample of 2499 IPOs of ordinary shares by firms on the London Stock Exchange. ${ }^{3}$ In addition we require that stock price/return data for issuers and market capitalisation data must be available on the London Share Price Database.

The listing methods in the sample, as defined by the LSPD G8 codes, comprise placements $(81.3 \%)$, offers for sale at fixed price $(11.5 \%)$, offer for sale by tenders (2.1\%), and offer for sale by subscriptions (1\%), placing combined with open offer $(0.6 \%)$, placing combined with intermediaries offer $(0.5 \%)$, and lastly placing combined with offer for sale (3\%). Table 1 shows the distribution of the IPOs by type and by year. The table reveals that there is considerable time variation in the number

\footnotetext{
${ }^{3}$ The exclusion of such firms is typical of the literature (e.g. Espenlaub et al, 2000; Goergen et al, 2007). However, our results are similar if we include banks and financial stocks.
} 
of IPOs, with peaks occurring in the pattern of IPOs. The more recent increase in numbers coincides with the opening of the AIM market on the LSE.

[Table 1 about here]

\section{Calculation of abnormal returns}

We measure returns for IPOs and the control sample of firms using monthly returns from the London Share Price Database (LSPD). The market capitalisations of all firms in January of each year were also obtained from the LSPD database. We measure event time abnormal returns using two metrics. Our main method is the Buy and Hold Abnormal Return (BHAR):

$$
B H A R_{i \tau}=\left[\prod_{t=1}^{\tau}\left(1+R_{i t}\right)\right]-\left[\prod_{t=1}^{\tau}\left(1+R_{i t}^{b}\right)\right]
$$

where $\tau$ is the period of investment in months commencing at the start of the month following flotation, ${ }^{4} R_{i t}$ is the return on security $i$ in month $t$. The benchmark return, $R_{i t}^{b}$, is formed in three ways: our first (and preferred) method is to use decile reference portfolios, constructed as described below. Two variants of this approach are employed: an equally weighted control portfolio and a value-weighted one. The $B H A R$ derived from these benchmarks represents the abnormal return on the portfolio of IPOs compared to that of an equivalently size-controlled passive investment portfolio with no monthly rebalancing. Although we have a strong preference for control portfolios, we also report a third version of the BHAR results using a matched-firm approach. For the matched-firm control an IPO firm that went public in a given year is matched by a listed firm with the closest available market capitalisation at January of the same year. For an IPO firm that does not have a matching firm the returns of which last for the whole test period, we substitute the returns of the next available size-matched firm at the point of delisting. By necessity, this involves the effective re-balancing of the control portfolio.

\footnotetext{
${ }^{4}$ As an anonymous referee has pointed out, this is a standard practice in the literature and excluding the month of the issue itself minimises the impact of any initial under-pricing and underwriter price support in immediate after-trading. It has the further advantage of ensuring that the returns measured in this paper would have been realisable by investors. Including first day returns would capture returns only to the group of investors who received a full allocation of stock in the issue.
} 
When the estimation of abnormal returns is based on a benchmark, such a benchmark should, in principle, match the characteristics of the event firm as closely as possible. Lyon et al. (1999) emphasised that a careful construction of reference portfolios should be made to eliminate the new listing and rebalancing biases. The benchmark and the event portfolio should, in principle, be a plausible and investable opportunity set, in accordance with Liu and Strong (2008). Thus our main benchmark is based upon initial value-weightings. However, we also check our results against an equally weighted benchmark, as if IPOs are in general of average size within their deciles, such a benchmark may be viewed as more appropriate than a value-weighted benchmark. Our reference, or benchmark, portfolios are purged of 5 year IPO firms listed in London stock exchange market during the period of study (January 1975December 2007), as suggested by Loughran and Ritter (2000). Our choice of sizedecile control portfolios, rather than size and book-to-market portfolios, follows Loughran and Ritter (2000). Besides the "behavioural timing" arguments put forward by Loughran and Ritter, there is a further practical reason for not using book-tomarket controls in a UK context. Whereas the LSPD data is comprehensive, covering returns and market capitalisations for all UK stocks, the same is not true of Datastream or any other UK source of book-to-market values. Some firms simply have missing book values (this is particularly true for the early years of our sample) but for some sectors Datastream does not have market-to-book ratios. To construct the size control portfolios, each year all UK firms are ranked according to their market capitalisation in January, and decile portfolio are constructed with equal number of firms in each decile. The return for each size control portfolio is then tracked from January of year $t$ for $\tau$ months, with the returns being value-weighted according to their initial market capitalisations. These control portfolios do not therefore require re-balancing and follow the principles set out in Liu and Strong (2008). Each IPO is then assigned a control portfolio based on its market capitalisation, defined as the offering price times the number of shares outstanding at the first day of trading.

A further problem that we confront both in the IPO sample and the benchmark portfolio sample is that of firms that de-list within the 60 month measurement period. Liu and Strong (2008, p.2255) replace de-listed firm returns by either zero or the riskfree rate. They find similar results in both cases. Lyon, Barber and Tsai (1999) and 
Mitchell and Stafford (2000, p.298) replace all de-listed firms by the benchmark return. This has the potential to create an upward bias in the estimated BHAR returns, since some of these de-listings are bankruptcies. While CRSP deals with de-listings by accounting for the final return, including bankruptcies, not all of these effects of bankruptcies are actually taken into account. First, some of these corrections are made several months or even several years after any de-listing. Second, a proportion of de-listed returns remain 'missing' permanently in CRSP. ${ }^{5}$ While CRSP record a final return based upon the firm's worth at delisting, the LSPD does not provide such a service. Under LSPD, de-listed firms have a missing value, although the reason for delisting is recorded. In computing BHAR returns, de-listed firms were treated on the basis of the following rule. If a de-listed firm has preserved its value (such as a merger or an acquisition), we replace the return of that firm by the return of the benchmark. If the delisting is due to a total loss of value (bankruptcy), we replace the return by -1 . In making this distinction, we use the LSPD G10 description. The most important codes are 7, 16, 20 and 21. As can be seen from the description in Appendix 1, these types of delisting are most likely to be stocks that are either worthless or a long way from giving shareholders any terminal value, and so we treat these cases as if investors lost all their investment. By contrast, the remaining types of de-listing would seem to be value preserving.

\section{Test statistics in event time}

For each $\tau$ we calculate the conventional t-statistic as

$t_{\tau}=\frac{\bar{B} \overline{H A} \bar{R}_{\tau}}{\sigma\left(B H A R_{i \tau}\right) / \sqrt{N}}$

where $\bar{B} \overline{H A} \bar{R}_{\tau}$ is the (cross sectional) sample mean, $\sigma\left(B H A R_{i \tau}\right)$ is the crosssectional standard deviation, and $N$ is the number of IPO firms. Because the data is likely to be skewed, we correct for skewness using Johnson's (1978) correction

$$
S K a d j-t_{\tau}=\sqrt{N}\left(S+\frac{1}{3} \hat{\gamma} S^{2}+\frac{1}{6 N} \hat{\gamma}\right)
$$

where $\hat{\gamma}$ is the coefficient of skewness, and $S \equiv \bar{B} \overline{H A} \bar{R}_{\tau} / \sigma\left(B H A R_{i \tau}\right)$. This adjustment was advocated by Lyon et al. (1999) because of the suspected skewness of

\footnotetext{
${ }^{5}$ http://www.crsp.chicagogsb.edu/resources/files/crsp_white_paper_delist_returns.pdf
} 
BHAR returns. They use the standard bootstrap procedure with bootstrap sample size of $N / 4$. However, this standard bootstrap does not address the questions of crosssectional correlation and heteroscedasticity. To our knowledge, the first problem cannot be addressed in a cross-sectional test, and although Mitchell and Stafford (2000, pp 304-6) argue for t-statistics corrected for cross-sectional dependence these are not t-statistics that are simultaneously corrected for skewness. In any event, Mitchell and Stafford (2000) have a strong preference for calendar time methods to allow for cross-sectional correlation. Neither is the second problem of heteroscedasticity addressed by the ordinary bootstrap. We advocate the use of the wild bootstrap instead. This procedure has the merit that it preserves the first and second moments of the parent distribution. The difference between the ordinary and wild bootstrap is simple. Let the residuals from a regression be $\hat{\varepsilon}_{i}$ (in our case $\left.\hat{\varepsilon}_{i}=B H A R_{i}-\bar{B} \overline{H A} \bar{R}\right)$. In the regular bootstrap we resample by drawing $N^{*}<N$ residuals, $\hat{\varepsilon}_{i}^{*}$, with replacement from the series $\hat{\varepsilon}_{i}$. In the wild bootstrap we create the bootstrap residuals $\hat{\varepsilon}_{i}^{*}$ as the product of the original residuals and an independent random variable, $\eta_{i}$, with zero mean and unit variance. This guarantees that the bootstrap variance will be the same as that of the parent distribution. For example, $\eta_{i}$ can be standard normal and hence $E\left(\hat{\varepsilon}_{i}^{*}\right)=E\left(\eta_{i}\right) E\left(\hat{\varepsilon}_{i}\right)=0$ and $V\left(\hat{\varepsilon}_{i}^{*}\right)=V\left(\eta_{i}\right) V\left(\hat{\varepsilon}_{i}\right)=V\left(\hat{\varepsilon}_{i}\right)$

However, if the data is skewed, re-sampling based on the standard normal will yield zero skewness since $E\left(\eta_{i}^{3}\right)=0$. To preserve skewness, Liu (1988) and Mammen (1993) suggest ways of obtaining $E\left(\eta_{i}^{3}\right)=1$. One suggestion is

$$
\eta_{i}=\left\{\begin{array}{lll}
\frac{1+\sqrt{5}}{2} & \text { w.p. } & p=\frac{\sqrt{5}-1}{2 \sqrt{5}} \\
\frac{1-\sqrt{5}}{2} & \text { w.p. } & 1-p
\end{array}\right.
$$

This will guarantee that $E\left(\eta_{i}\right)=0$, and $E\left(\eta_{i}^{2}\right)=E\left(\eta_{i}^{3}\right)=1$. However, this scheme will not preserve the kurtosis of the parent distribution since $E\left(\eta_{i}^{4}\right)=2$. An alternative scheme (see Davidson et al. (2007)) is to use

$$
\eta_{i}=\left\{\begin{array}{ccc}
1 & w . p . & p=\frac{1}{2} \\
-1 & \text { w.p. } & 1-p
\end{array}\right.
$$


This will preserve mean, variance and kurtosis $\left(E\left(\eta_{i}\right)=0\right.$, and $\left.E\left(\eta_{i}^{2}\right)=E\left(\eta_{i}^{4}\right)=1\right)$ but not skewness $\left(E\left(\eta_{i}^{3}\right)=0\right)$. Achieving both preservations is not possible. Davidson et al. (2007) suggest some combination that will achieve partial refinement. However, here we advocate combining the skewness adjusted t-statistic with the kurtosis preserving wild bootstrap. Assuming that the skewness adjustment of Johnson (1978) is reasonably accurate, the parent distribution of the adjusted statistic will be expected to be symmetric. Therefore, achieving $E\left(\eta_{i}^{4}\right)=1$ will be more important than achieving $E\left(\eta_{i}^{3}\right)=1$. Accordingly, we adopt this combined SkewnessAdjusted and Kurtosis Preserving Bootstrap approach in our tests.

\section{Calendar time methodology}

When calculating returns in calendar time, we have the choice between measuring returns relative to a risk-controlled benchmark, or using a regression-based framework. We can usefully summarise all the approaches used to estimate abnormal returns as follows. Let $R_{\tau, t}$ be a time series of a portfolio of IPO returns of companies that were born within the previous $\tau$ months. In general, calendar time tests can be seen as testing for the significance of $\alpha$ in a time series model

$$
R_{\tau, t}=\alpha+\left(R_{\tau, t}\right)^{E}+\varepsilon_{t}
$$

where $\left(R_{\tau, t}\right)^{E}$ is the required return and $\varepsilon_{t}$ is a zero mean disturbance term. We can think of this expected return either in terms of a factor model (for example the CAPM or the Fama-French three factor model) or some benchmark, $R_{b t}$, where the benchmark is matched on the basis of firm-specific characteristics, such as market capitalisation. If we write expected return as:

$$
\left(R_{\tau, t}\right)^{E}=R_{f t}+\beta\left(R_{b t}-R_{f t}\right)
$$

we can then view the simple CTAR as being a special case that has the additional restriction that $\beta=1$. Lyon et al. (1999, p. 197) emphasise that such simple CTAR methods appear to be better specified (and more conservative) than the Fama-French three factor approach, "suspecting" that the former "generally dominates" the latter for two reasons: first, the assumed linearity in factor exposures inherent in the FamaFrench model in calendar time; second, the problem of interactions between the 
factors. Mitchell and Stafford (2000, p.321) also favour the CTAR methodology rather than the Fama-French regression-based approach, noting that because it suffers from fewer statistical flaws "more faith should be placed in these results". An additional concern for UK researchers is that it is far from clear that the Fama-French model is entirely appropriate in a UK context. Issues raised include the questions of whether the model adequately describes the cross-section of expected returns in the UK, whether other factors (such as R\&D expenditure to market value) may actually dominate the Fama-French factors in the explanation of this cross-section, and whether results may anyway be highly sensitive to the precise construction of the factors (Gregory, Harris and Michou, 2001; Al-Horani, Pope and Stark, 2006; Michou, Mouselli and Stark, 2007). For these reasons there seems to be little reason to favour calendar time regressions based upon a Fama-French model, and so we do not report results on this basis.

In more general terms we can think of (5) as a model that allows for some variation between the characteristics of the benchmark portfolio and the characteristics of the IPO portfolio. If the benchmark perfectly matches the risk characteristics of the IPO portfolio, then $\beta$ should be unity. However, if the IPO portfolio has more or less risk than the benchmark ${ }^{6}$, then allowing $\beta$ to vary can take account of this. The approach is not new, for example the same model is employed in an investigation of UK IPOs by Espenlaub, Gregory and Tonks (2000), but a further advantage of the regression approach, not previously exploited in the literature, is that it allows more sophisticated approaches to the well-known problem of heteroscedasticity (Mitchell and Stafford, 2000) in calendar time portfolios to be accommodated. The first, and most simple approach to the problem that we employ is the estimation of robust standard errors using White (1980) corrections. The alternative approach is to use GLS. Assuming an equally weighted portfolio and that all returns are iid at time t, a $\tau$-month holding period portfolio return is obtained as

$$
R_{\tau, t}=\frac{1}{n_{\tau, t}} \sum_{i=1}^{n_{\tau, t}} R_{i t}^{(\tau)}
$$

\footnotetext{
${ }^{6}$ For example, the mean IPO firm does not have exactly the same mean market capitalisation as the benchmark.
} 
where $n_{\tau, t}$ is the number of firms in the portfolio and $R_{i t}^{(\tau)}$ is the return of a firm $i$ that was born within the last $\tau$ months.

The variance of this portfolio is

$$
\operatorname{Var}\left(R_{\tau, t}\right)=\frac{1}{\left(n_{\tau, t}\right)^{2}} n_{\tau, t} \sigma^{2}=\frac{1}{n_{\tau, t}} \sigma^{2}=\sigma_{t}^{2}
$$

So even under the unrealistic assumption that returns are iid, the portfolio variance will be time varying and will depend on the number of IPO stocks included in the portfolio. Unfortunately, the portfolio variance will probably be more complex than (7) because asset returns are not iid.

When heteroscedasticity has a simple form as in (7), one way of dealing with this problem is to standardise the residuals such that they have a constant variance. For example, in a simple regression like

$$
R_{\tau, t}=\alpha+\beta R_{b t}+u_{t}
$$

If $\operatorname{Var}\left(u_{t}\right)=\omega_{t}^{2}$, then we can use the fact that $\operatorname{Var}\left(u_{t} / \omega_{t}\right)=1$ and standardise the equation above by dividing the whole equation by $\omega_{t}$. GLS involves replacing the unknown $\omega$ with some estimate. One simple case is to set $\omega_{t}=1 / \sqrt{n_{\tau, t}}$. This is identical to Mitchell and Stafford's (2000) suggestion of estimating ${ }^{7}$

$$
\sqrt{n_{t}} R_{\tau, t}=\sqrt{n_{t}}\left(\alpha+\beta R_{b t}+u_{t}\right)
$$

A more flexible approach would be to estimate the variance, since we do not know its exact form. Here, we assume that it is a linear function of the number of the firms entering the portfolio. Thus, we assume that the variance can be approximated by some function of $\hat{\delta}_{0}+\hat{\delta}_{1} n_{t}$. To ensure that the variance is positive we set $\operatorname{Va} r_{t}\left(u_{t}\right)=\exp \left(\hat{\delta}_{0}+\hat{\delta}_{1} n_{t}\right)$. To operationalise this we first obtain the unrestricted residuals $\hat{u}_{t}$ from

\footnotetext{
${ }^{7}$ However, the authors argue against this transformation since it "completely defeats the purpose of forming calendar-time portfolios" (p.317). Instead, they use a bootstrapping procedure to compute critical values.
} 


$$
R_{\tau, t}=\alpha+\beta R_{b t}+u_{t}
$$

Then estimate the regression

$$
\log \left(\hat{u}_{t}^{2}\right)=\delta_{0}+\delta_{1} \log \left(n_{t}\right)+\text { error }
$$

Finally, we set $\operatorname{Var}\left(u_{t}\right)=\exp \left(\hat{\delta}_{0}+\hat{\delta}_{1} \log \left(n_{t}\right)\right)$. As we show below, the GLS formulation appears to offer a better fit in terms of adjusted R-squared statistics, although the inferences from both the GLS and OLS with robust (White (1980) corrected) standard errors are broadly similar.

\section{Results}

\section{Buy and hold returns in event time}

Our first results, presented in Table 2, show the BHARs derived from an equallyweighted size decile control portfolio. We report the returns from all markets, excluding privatisations, in this Table. Panels A to $\mathrm{C}$ then report the results from the use of an equally weighted, value weighted and size control firm respectively. The BHAR in Panel A falls from an insignificant $+0.8 \%$ after 6 months to $-3.4 \%$ (significant at the 5\% level) after 12 months, becoming highly significant thereafter and continuing to fall to $-10.8 \%$ after 24 months, $-16.4 \%$ after 36 months, $-29.2 \%$ after 48 months and $-47.6 \%$ after 60 months. ${ }^{8}$ All abnormal returns are skewed and leptokurtic. It is worth recording that the IPO buy and hold return itself is highly skewed and leptokurtic throughout the period, and that the benchmark is also skewed and leptokurtic, but to a lesser extent. We also report medians, and note that the median performance is considerably worse than the mean throughout. Our wild bootstrap test statistic should adequately deal with outliers, but as a test of whether outliers are influencing the performance we Winsorise the abnormal returns at the $1 \%$ and 99\% levels, reporting a truncated mean and a t-test based upon the truncated BHARs. The truncated mean is less negative than the overall mean, but is highly significant. Truncated mean BHARs are $-11.3 \%$ after 36 months and $-30.8 \%$ after 60 months.

\footnotetext{
${ }^{8}$ Note that our IPOs are observed up until the end of 2004. However, at the time of writing LSPD returns were only available until end 2007. Thus whilst the 36 month BHARs can be calculated for all stocks, the full 48 month and 60 month BHARs can only be estimated for IPOs that took place up until the end of 2003 and the end of 2002 respectively.
} 
Panel B of Table 2 shows the results from a comparison against the value-weighted size-decile control portfolios. In general, the BHARs are smaller in absolute value than those obtained with an equally weighted benchmark. Again the BHAR is insignificantly positive after 6 months, falling to a marginally significant $-3.0 \%$ after 12 months. Beyond 12 months the rate of decline accelerates, with abnormal returns reaching $-9.2 \%$ after 2 years, $-12.6 \%$ after 3 years, $-19.5 \%$ after 4 years and $-31.6 \%$ after 5 years. The skewness and kurtosis of the BHARs is greater than under the equally weighted benchmark, the difference being attributable to the smaller levels of skewness and kurtosis found in the value-weighted control portfolio compared to those of the equally-weighted portfolio. As with the equally weighted benchmark, medians are more negative than the means. However, the truncated means are smaller in terms of absolute value, and although generally significant, this is not the case for the 30 and 36 month BHARs. However, after 36 months the truncated mean falls and becomes increasingly significant, reaching a highly significant $-19.7 \%$ for the 60 month BHAR.

Finally, in Panel $\mathrm{C}$ we present the results from matching against a control firm portfolio. Although the pattern of abnormal returns is consistent with those from the other two methods, we note that the abnormal returns here are considerably larger in terms of absolute magnitude, being $-7.7 \%$ after 12 months, $-30.1 \%$ after 36 months, and a massive $-69 \%$ after 60 months. These abnormal returns have considerably less skewness and kurtosis than is found under the portfolio-control methods. However, the reason for this is that the matched firms themselves have (buy and hold) returns that are highly skewed and leptokurtic. Last, medians and truncated means are smaller in absolute magnitude than the overall means, but are still highly significant.

\section{[Table 2 about here]}

Whilst one might take comfort from the fact that all three benchmarks lead to a statistically consistent conclusion, the large differences in the size of the BHARs is troubling. As a robustness check on these figures, we calculated a conventional cumulative abnormal return using the value-weighted size benchmark. The CARs turn out to be smaller in magnitude than the BHARs, but remain significant at all 
horizons greater than 6 months using either a simple t-test or our wild bootstrap alternative. Although the problems of positive bias in CARs are well known (e.g. Kothari and Warner, 1997) there is a hint in the comparison between the CARs and BHARs of the compounding problem argument of Fama (1998), Mitchell and Stafford (2000), and Gompers and Learners (2003) where the buy-and hold return method can magnify underperformance, even if it occurs in only a single sub-period.

\section{Sub-analysis of performance based upon listing market}

Both the USM and the AIM had, or have, less onerous entry requirements than those that apply to firms listing on the main market. In particular, the trading history of such firms is shorter and the average market capitalisation of firms on these markets is smaller. Goergen et al. (2007) show that smaller firms have different long run performance characteristics. This motivates the partitioning of our sample into Main Market, AIM and USM firms. ${ }^{9}$ The long run performance of these categories is shown in Tables 3, 4, and 5 respectively. In all cases, Panels $\mathrm{A}$ to $\mathrm{C}$ follow the benchmarks for Table 2, i.e. Panel A reports results against an equally weighted benchmark, Panel B against a value weighted benchmark, and Panel C against a sizematched firm benchmark. Of our sample of 2,499 firms, $50.2 \%$ list on the main market, $39.6 \%$ list on AIM, and $10.2 \%$ list on the USM.

\section{[Table 3 about here]}

Turning first to the main market, results vary according to the benchmark selected. Using an equally weighted benchmark (Table 3, Panel A), returns start off as being significantly positive under the equally weighted metric at the one and two year horizons (the latter being $4.3 \%$, significant at the $10 \%$ level), before tailing off to a highly significant $-19.2 \%$ after 60 months. The median is substantially below the mean for all horizons, although we note that the truncated mean is not significantly different from zero. When the value-weighted benchmark is used (Panel B), none of the longer horizon returns are significantly different from zero, although the medians are large and negative, and only the 6 month returns is significantly positive. Finally, when the size-matched benchmark is employed, returns at horizons beyond 36 months

\footnotetext{
${ }^{9}$ Note that we do not include UK privatisations in any of these Tables, and do not report the returns to privatisations for reasons of space. However, we note that applying the same approach to privatisations results in significant positive returns to investors.
} 
(42 months in the case of the truncated mean) are significantly negative. Given this ambiguity between the metrics, it is hard to conclude that the long run performance of main market IPOs is reliably different from zero. This suggests that the overall results in reported in Table 2 are driven by AIM and USM IPOs.

\section{[Table 4 about here]}

Turning first to AIM, in Table 4 we see clear evidence of substantial and highly significant negative performance by AIM IPOs, whichever metric is employed. In Panel A, using the equally weighted metric, buy and hold abnormal returns range from $-11 \%$ after 12 months, to $-43.3 \%$ after 36 months and $-111.7 \%$ after 60 months. Using our value-weighted benchmark, the abnormal returns for these periods are $9.6 \%,-36.1 \%$ and $-74 \%$ respectively. Finally, Panel C employs the size-matched firm benchmark and yields results of $-16.9 \%,-60.6 \%$ and $-172.1 \%$ for the 12,36 and 60 month periods. Neither medians nor truncated means suggest that any of these results are being driven by outliers, with the truncated means following a similar pattern to the means, being significant at all horizons greater than 12 months. In short, the performance of AIM IPOs is extremely poor.

One way that we can test whether our results for AIM are reflective of the nature of firms that float on more lightly regulated markets is to look at its predecessor, the USM. The USM started in 1980 and was wound up in 1996, effectively being made irrelevant by changes in listing rules and the introduction of AIM in 1995, with the number of USM IPOs falling away sharply in the 1990s as the difference between USM and Main Market listing requirement narrowed. The results for USM IPOs are presented in Table 5. When we examine the BHARs of USM stocks we see a similar pattern to that which emerges for AIM stocks. At all horizons beyond 6 months, returns are substantial and negative. Indeed, after 60 months these abnormal returns are well in excess of $-100 \%$ whichever metric is used. As in the case of the AIM stocks, neither medians nor means suggest that these large negative abnormal returns are attributable to an outlier effect This leads us to inspect the data more closely to see what might be driving these abnormal returns. A key reason that emerges is that a substantial percentage of firms that list on the USM were delisted for reasons that can be classified as liquidation or administrative receivership. Table 6 shows the detailed breakdown of this rate of attrition according to the market of listing. After 36 months, $1.2 \%$ of Main Market IPOs have delisted for this reason, compared with $4.3 \%$ of AIM 
stocks and $4.3 \%$ of USM stocks. Note that beyond year 3, AIM and Main Market stocks do not have complete histories (recall that our IPO period ends in 2004 and we record outcomes up to end 2007 only), but calculating survival rates on the basis of the available data reveals that $11.8 \%$ of USM firms enter bankruptcy by the end of the 5 years following listing, compared to $9.5 \%$ of AIM stocks and 3.6\% of Main Market stocks. ${ }^{10}$ Finally, note that attrition rates continue to be substantial beyond the 5 year horizon, so to some extent these low returns might be reflective of market prices anticipating bankruptcy beyond the 5 year post-IPO cut-off.

\section{[Table 5 about here]}

\section{[Table 6 about here]}

\section{Evidence on timing}

Our next tests investigate the timing issue. Under both behavioural timing and pseudo-timing hypotheses, managers respond to movements in market prices. Chan et al. (2007) run regressions of share repurchase activity on past market performance to test for evidence of market timing. However, they investigate share repurchase decisions, where one might reasonably assume managers are able to respond fairly quickly to changes in market prices, provided a buy-back programme is in operation. The authors use monthly data to investigate their hypotheses, which seems entirely reasonable for buy-backs. By contrast, the planning horizon for IPOs is likely to be far longer than a month. Quite whether quarterly or annual data are more appropriate to investigate timing is debatable, but here we choose annual data. If pseudo-timing exists, we should observe a positive relationship between IPO activity and past market performance. IPO activity is proxied by two variables. The first is simply the relative number of IPOs in a particular year, $n_{t}$. This relative number of IPOs in year $t$ is given by $n_{t}=100 \times\left(I P O n_{t} / M n_{t}\right)$ where $I P O n_{t}$ is the number of IPOs in year $t$, and $M n_{t}$ is number of listed firms in the market in the same year. This proxies for the IPO activity in year $t$ in terms of numbers. The second activity measure is the relative market value of IPOs in the same year, $v_{t}$. The IPO relative value in year $t$ is given

\footnotetext{
${ }^{10}$ We suspect that were we to calculate full 5 year survival rates at end of 2009 for our 2003 and 2004 IPOs, the number of AIM bankruptcies would be considerably higher.
} 
by $v_{t}=100 \times\left(I P O v_{t} / M v_{t}\right)$ where $I P O v_{t}$ is the value of all IPOs issued in year $t$, and $M v_{t}$ is the total market capitalisation in the same year. This second variable proxies for the IPO activity in year $t$ in terms of value.

Explanatory factors are the lagged dependent variable, average (excess) market return $\left(m_{t}\right)$, the return on SMB $\left(s m b_{t}\right)$, and the return on HML $\left(h m l_{t}\right)$ for a given year. To investigate the issue, we run an OLS regression of the form:

Dependent $=$ function of lagged (Dependent, co-dependent, $\mathrm{m}, \mathrm{smb}, \mathrm{hml}$ ) and Trend . The lagged dependent variables capture possible cyclical behaviour, while the trend captures the long term growth of the economy. The other factors capture market timing. SMB and HML factors are from Gregory and Michou (2007) and formed as described in Gregory, Harris and Michou (2001). The regressions are run in two steps, a full model and a restricted model, and all are estimated using White (1980) corrected standard errors.

The results are shown in Table 7, Panel A (with relative number as the dependent variable) and Table 7, Panel B (with relative value as the dependent variable). The adjusted R-squared values are high, particularly for the relative number regression. Which lags are significant depends upon whether the relative number of IPOs or the relative value of IPOs are taken as the dependent variable, but both regressions indicate that both short term and long term cyclical impacts may be present. However, the interpretation of the nature and length of this cycle differs between the two regressions. In terms of relative number regressions, both lagged market returns and lagged SMB returns are significant predictors of IPO activity, an effect consistent with the pseudo-timing hypothesis. IPOs tend to be smaller firms, and our evidence indicates that more flotations take place when markets are performing strongly and smaller firms in particular are performing well. The trend term in the Panel A regressions shows that there is a long term upward drift in IPO activity over time. Last, there is no evidence that HML influences the number of IPOs. The Panel B regressions with relative value of IPOs as the dependent variable show a different dynamic in terms of the lagged variables compared to the relative number regressions. Although lagged market returns remain a significant predictor of IPO activity in value terms, the SMB factor now exhibits a negative relationship with IPO value, but only 
at a 2 year lag. This difference between relative number and relative value regressions is consistent with large IPOs tending to follow periods of smaller firm under-performance. Last, there is a hint that lagged HML is positively related to IPO value, but this effect fails to be significant in the restricted regression. Last, the relative value trend is positive, at least in the restricted regression.

[Table 7 about here]

\section{Calendar time results}

As Chan et al. (2007, p.2684) state, a "key implication of pseudo-timing is that while abnormal performance may exist when measured in event time, this result should not exist when evaluated in calendar time". Accordingly, having shown that some form of market timing appears to be taking place in observed IPO activity, we now turn to the analysis of IPO portfolios formed in calendar time. We employ two weighting schemes. The first is a simple equal weighting, where in any month each firm that has experienced an IPO in the previous 12, 24, 36, 48 or 60 months is included in the portfolio, so that in any given month, $t$, the weight given to that firm is $1 / N_{t}$, where $N_{t}$ is the number of firms in that portfolio in month $t$. The second is a value weight, where each firm is weighted according to its market capitalisation, $M_{i, t}$, at the time of the initial IPO. The weight given to any firm in month $t$ is therefore:

$$
M_{i, t} / \sum_{j=1}^{N_{t}} M_{j, t}
$$

Note that in both cases the benchmark return for the CTAR calculation is that IPO's value-weighted size-control decile portfolio return. Whether value-weighted CTARs or equally weighted CTARs are better specified is an empirical question that is yet to be resolved. One feature of value-weighted calendar time abnormal returns that has not been discussed in the literature is that in markets with an expected positive return and dividend payout rates of less than $100 \%$, value-weighted abnormal returns will tend to place more weight on recent issues in the portfolio of CTARs. To see this, first assume that IPOs (or any other event of interest) occur randomly through time. A priori, in, say, the 60 month CTAR portfolio, the weights given to IPOs in the past 12 months will be $12 / 60$, the weight to IPOs in the past 13-24 months $12 / 60$, and so on. However, positive expected nominal returns and less than $100 \%$ payout rates 
imply that the market capitalisations of all firms rise through time, partly through an inflation effect and partly through a real expected rate of return effect. The consequence is that on average, weights will no longer be evenly distributed through time even if the IPOs themselves are, because more recent IPOs will tend to have higher market capitalisations than older IPOs. Of course, if IPOs are not randomly distributed through time then the weighting for any individual 12 monthly period may not be $12 / 60$, but the argument that recent IPOs have greater weight in the value weighted portfolio than the equally weighted one will still hold. In our portfolios this is indeed the case. The weightings to up to 12 months through to 48 to 60 month portfolios for the equally-weighted CTARs are, respectively, 29.5\%, 21.6\%, 18.5\%, $15.4 \%$ and $15 \%$, whilst those for the value-weighted scheme are, respectively, $32.3 \%$, $22 \%, 17.5 \%, 14.5 \%$ and $13.8 \%$. This matters if abnormal returns occur at a nonlinear rate through time. The BHARs reported in Table 2 suggest that the rate of abnormal return is at its smallest in the first 12 months - indeed, the first 6 months show a positive return. A second issue with value-weighted returns is that they are less likely to detect abnormal performance if this is concentrated in smaller firms (Chan et al., 2007; Loughran and Ritter, 2000).

Turning to the results themselves, in Table 8 we present results using the basic CTAR method described in Lyon et al. (1999) and Mitchell and Stafford (2000). Panel A shows the results from the equally-weighted portfolio. Monthly returns are significantly negative for all periods beyond 12 months. For the 24 and 36 month returns are $-0.50 \%$ and $-0.48 \%$ respectively. For the 48 month period returns are $0.37 \%$ per month, and after 60 months returns they are a significant $-0.41 \%$ per month. The negative abnormal returns implied by the CTAR method are actually greater than those from the value-weighted benchmark BHAR returns for 24 and 36 month horizons, which does not support a pseudo-timing argument. However, the CTAR returns suggest that the rate of under-performance in IPOs slows somewhat after 36 months, a result also found in an earlier investigation of UK IPOs in Espenlaub et al. (2000). The conclusion from the equally-weighted CTAR analysis seems clear - the under-performance of IPOs is real enough, supportive of a Loughran and Ritter (2000) behavioural timing explanation of IPOs, and not the result of "pseudo-timing". When we conduct the same analysis using value-weighting, 
reported in Panel B of Table 8, the results are simply insignificant. At least two explanations are possible for this divergence between equally-weighted and valueweighted returns. The first is that abnormal returns are concentrated in smaller firms. For the US, Brav and Gompers (1997) show that under-performance is concentrated in smaller non-venture capital backed IPOs. However, this is not entirely consistent with earlier evidence for the UK. Espenlaub et al. (2000, Table 2) find that although underperformance is concentrated in the low deciles, the very worst decile for IPO performance is the largest. ${ }^{11}$ We show below that size is indeed a major factor influencing these value-weighted calendar time returns.

\section{[Table 8 about here]}

One problem with the basic CTAR analysis is that it relies on simple t-tests and also assumes that the portfolio of firms undertaking an IPO has exactly the same risk as the benchmark. As we argue above, better tests are available. Accordingly, in Table 9, we run the regression model implied by (4) above, employing White (1980) corrected robust standard errors. We also disaggregate our results showing Main Market, AIM and USM stocks separately. Panel A shows the results for the equallyweighted portfolio, which are broadly consistent with those from the basic CTAR method, except for the fact that results are somewhat more negative and generally more significant. The intercept terms, or "alphas", look close to the monthly abnormal returns from Table 2 Panel $\mathrm{B}$, and are always highly significant. The beta on the benchmark portfolios is on average slightly above one for the portfolio formation periods, but never significantly different from one for any individual formation period. Finally the adjusted R-squared figures suggest that the implied model of expected returns performs reasonably well in explaining the cross-section of observed returns. Taken as a whole, these results strengthen the picture painted by the CTARs in Table 8, Panel A. There again appears to be no support for a "pseudotiming" explanation of IPO returns. However, once again the value-weighted CTARs, reported in Panel B, yield abnormal returns that are wholly insignificant for all markets combined. Whilst the betas on the control portfolios are not too different from the equally weighted case, the standard errors of those betas have increased and

\footnotetext{
${ }^{11}$ Although they note that these are a small number of observations in this group. Nonetheless, the median abnormal return of these 8 firms is not supportive of an "outlier" effect.
} 
the adjusted R-squared figures are well below those of the equally weighted CTAR model for all portfolio formation periods, suggesting that a value-weighted model does a poorer job of explaining the cross-section of returns than an equally weighted model.

\section{[Table 9 about here]}

Breaking the IPO market down into sub-categories, we see that in general the equallyweighted calendar time results confirm the results from the BHAR analysis in Tables 3-5. Note, though, that the 60 month CTAR for the Main Market is significantly negative at the 5\% level which contradicts the BHAR result based on a valueweighted benchmark, though not those based on either the equally-weighted or sizematched benchmarks. The results for AIM are unambiguous, and confirm longer horizon returns are significantly negative, although the scale of longer run underperformance is less than that under the BHAR metric. This is not altogether surprising, in that the CTAR method, as a single-period portfolio formation device, necessarily drops out those firms that are no longer available for investment. As a consequence, any calendar time portfolio that has substantial bankruptcies will tend to exhibit higher returns than an equivalent event time portfolio. Betas are significantly greater than unity, suggesting that AIM IPOs are, on average, riskier than a simple size adjusted benchmark would suggest. USM stocks have more mixed results in calendar time. The 24 and 60 month portfolios exhibit significant negative abnormal returns, but other portfolios are not significantly negative. However, whilst the valueweighted calendar time results for other markets are not significantly different from zero, for the USM they are. This suggests that size effects played out rather differently in the USM compared to other markets.

Our final GLS regressions are shown in Table 10. Panel A of the table shows the results from equally-weighting firms in the IPO calendar time portfolio. First, by comparing these results with those in Table 9 Panel A we can see that the GLS model does indeed appear to add to a simple White-corrected OLS model of abnormal returns, and that this is true for all the sub-portfolios. Furthermore, the results with respect to the significance of the under-performance of IPOs are strengthened. For all 
markets combined, there is a marginal increase in the under-performance of IPOs, but the significance is greater. All horizons, including the 12 month horizon, are now significantly below zero. Turning to the sub-analysis by market, the most striking difference between these results and the previous ones is that the Main Market returns are now significantly negative at the 24, 36 and 60 month horizons. Note that the scale of the abnormal returns is not very different from the Table 3 or Table 9 results but the abnormal returns are now significant, varying between $-0.2 \%$ and $-0.3 \%$ per month. AIM and USM results are both unambiguously negative under this method, with the size of the alphas being consistent with serious under-performance of between $-0.8 \%$ and $-1.5 \%$ per month for AIM, depending on the horizon, and $-1.1 \%$ and $-1.4 \%$ per month for USM stocks.

However, on a value-weighted basis, consistent with the results in Table 9, the results are generally insignificant, with only the USM recording significant negative abnormal returns, as in Table 9.

\section{[Table 10 about here]}

\section{Returns by relative size and type}

Given the large differences between value and equally weighted returns in calendar time, we now turn to a sub-analysis of the BHAR results which divides the sample according to the relative size of the IPO. It is important to classify IPOs by relative rather than absolute size because of the enormous changes in market capitalisation between the early and later years of our sample. To classify IPOs, break-points were obtained as follows. We first calculated the relative value of a given IPO by dividing its market value at issue by the total market capitalisation of all firms in January of that year. This produces the size of the IPO relative to its current market. We then divided IPOs into five quintiles. The smallest quintile (Q1) includes IPOs whose value was less than $0.0005 \%$ of the total market capitalisation at the time of issue, while the largest quintile (Q5) includes IPOs whose value was greater than or equal to $0.05 \%$ of the total market capitalisation. The resultant distribution is shown in the first panel of Table 11. Whilst any such categorisation may be viewed as somewhat 
arbitrary, the figures clearly show that the majority of our IPOs fall into the middle quintile, with the smallest proportion (3.6\%) in the largest quintile. Means and medians are not that different from each other in Q1-Q4, but are very different in Q5. ${ }^{12}$

Our tests of the effect of size and market on BHAR are reported in the lower panels of Table 11. In these regressions, BHAR is regressed on four size dummies, one for each quintile, with the intercept capturing the lowest quintile performance, and further dummies for AIM and USM. Although adjusted R-squared values are somewhat disappointing, we can see that the general impression from Tables 3-5 shows up in the regressions. Controlling for AIM and USM stocks, BHARs increase with relative size, all the way through to Q5, and the increases are significant. The implication is that controlling for AIM and USM effects, relatively large IPOs have positive abnormal returns whilst small IPOs have negative abnormal returns. The results also show that whilst USM, net of any size effects, does not yield results significantly different from zero, the strong implication of these Table 11 regressions is that USM IPOs had significantly negative abnormal returns even after size has been controlled for. For example, the coefficients imply that on an equally weighted basis, simply by being listed on the USM, the average IPO will under-perform by an additional 76\% after 3 years, and that even on a value-weighted basis this effect is $-68 \%$ after 3 years.

\section{[Table 11 about here]}

\section{Conclusion}

Our results clearly show that in event time, IPOs under-perform, and under-perform significantly. We place most emphasis on the performance measured relative to our value-weighted control portfolios, and under that metric IPOs under-perform by around $12.6 \%$ after three years and by $31.6 \%$ after 5 years. Under-performance is greater when either equally-weighted control portfolios are used as the benchmark, or when a matched-firm approach is used. Under the pseudo-timing hypothesis of Schultz (2003), such observed under-performance of IPOs in event time ex post is not indicative of under-performance ex ante, and he argues strongly in favour of calendar time portfolio tests. A calendar time portfolio test amounts to investing a fixed

\footnotetext{
${ }^{12}$ It is perhaps worth noting that large IPOs in this quintile include such well-known firms such as Wellcome, Vodafone, Norwich Union and Orange.
} 
amount of cash in IPO portfolios each month. The arguments and simulations used by Schultz do not require any particular weighting scheme for these calendar time portfolios, and neither do his US results appear to be sensitive to the choice of weighting. We examine results using both equally weighted returns and valueweighted returns in calendar time.

Whilst it is clear from our analysis that timing effects exist, the equally weighted calendar time results lead us towards dismissing a pseudo-timing explanation of IPOs. These CTARs are indicative of substantial under-performance of IPOs, which is not compatible with a pseudo-timing hypothesis. In contrast, our results are in keeping with the behavioural timing hypothesis of Loughran and Ritter (2000). Using the simple CTAR approach of Lyon et al. (1999) we show strong under-performance for all horizons up to 60 months post IPO. More complex analyses using a regression framework which controls for heteroscedasticity show significant under-performance of between $-0.6 \%$ and $-0.7 \%$ per month after 36 months, and between $-0.5 \%$ and $0.6 \%$ per month after 60 months depending on whether a robust standard errors OLS or a GLS approach is used. These figures are in line with those implied by the BHAR approach. It is only when we value-weight these CTARs that we are unable to detect any abnormal performance. This does not, in our view, support a pseudo-timing argument; rather, it is indicative of under-performance being associated with smaller IPOs. Breaking down these results by market suggests that whether main market IPOs under-perform is somewhat sensitive to the metric employed. There is tentative evidence of under-performance using some benchmarks in event time, and definite evidence of under performance in calendar time. However, it is clear that this underperformance is less than that observed is AIM and USM markets, both of which exhibit highly significant under-performance. The other major result is that size plays an important part in determining the success of an IPO. Large IPOs outperform small IPOs, although even when size is allowed for, USM IPO stocks significantly underperform all other IPO stocks.

Of course, there are the usual caveats that our results are contingent upon the correct risk-adjusted benchmarks being employed in the analysis. Here, we have employed 
size-decile controls and size-matched firm controls. Some might argue for different matching procedures. We favour size-controls rather than, say, size and book-tomarket controls, for three reasons. The first two are theoretical. First, there is a growing body of evidence (Gregory et al., 2001; Al-Horani et al., 2003; Michou et al., 2007; Gregory and Michou, 2009) that suggests UK returns may not be entirely captured by either a Fama-French model or a model based on Fama-French style portfolios. Second, as Loughran and Ritter (2000) observe, if behavioural timing does occur, then more powerful tests result from using size-control portfolios than using size and book-to-market portfolios. Our third reason for choosing size-matching is pragmatic, in that it enables us to use the largest possible number of IPO and control firms, and avoids any possible survivorship biases affecting our results. Obviously, it is essential to properly match the risk of IPO firms and their benchmarks, and there is room for debate about how this should be done. Nonetheless, it is difficult to see how the scale of the underperformance we record for AIM and USM stocks can be attributed to a "bad model" problem. 


\section{References:}

Aggarwal, R. and Rivoli, P. (1990), 'Fads in the Initial Public Offering Market?' Financial Management, 19, pp.45-57.

Al-Horani, A, Pope, P.F. and Stark, A.W. (2003), 'Research and Development Activity and Expected Returns in the United Kingdom', European Finance Review, 7, pp 27-46.

Baker, M., Taliaferro, R. and Wurgler, J. (2006), 'Predicting returns with managerial decision variables: Is there a small-sample bias?' Journal of Finance, 61, 17111730 .

Barber, B. and Lyon, J. (1997), 'Detecting Long-Run Abnormal Stock Returns: The Empirical Power and Specification of Test Statistics', Journal of Financial Economics, 43, pp.341-372.

Barber, B.M. and John Lyon, D. (1996), 'Improved Methods for Tests of Long-Run Abnormal Stock Returns', working paper, University of California Davis.

Brav, A. and Gompers, P. (1997), 'Myth or reality? The Long-Run Underperformance of Initial Public Offerings: Evidence from Venture and Non-Venture CapitalBacked Companies', Journal of Finance, 52, pp.1791-1821.

Brave, A., Geczy, C. and Gompers, P. (2000), 'Is The Abnormal Return Following Equity Issuance Anomalous?’ Journal of Financial Economics, 56, pp.209-249.

Butler, A.W., Grullon, G., and Weston, J.P. (2005), 'Can managers forecast aggregate market returns?', Journal of Finance 60, pp 963-986.

Chan, K., Ikenberry, D.L., and Lee, I. (2007), 'Do managers time the market? Evidence from open-market share repurchases', Journal of Banking and Finance 31, pp.2673-2694.

Davidson, J., A. Monticini and Peel, D. (2007), 'Implementing the Wild Bootstrap Using a Two-Point Distribution', Economics Letters, 96, pp.309-315.

Dewenter, K. L. and Malatesta, P. H. (1997), 'Public Offerings of State-Owned and Privately-Owned Enterprise: An International Comparison', Journal of Finance, 52, pp.1659-1679.

Dichev, I. and Piotroski, J. (2001), 'The Long-Run Stock Returns Following Bond Rating Changes', Journal of Finance, 56, pp.173-203.

Espenlaub, S., Gregory, A. and Tonks, I. (2000), 'Re-assessing the Long-term Underperformance of UK Initial Public Offerings', European Financial Management, 6, pp.319-342.

Fama, E.F. (1998), 'Market Efficiency, Long-Term Returns, and Behavioural Finance', Journal of Financial Economics, 49, pp.283-306. 
Fama, E.F. and K.R. French (1992), 'The Cross-Sectional of Expected Returns', Journal of Finance, 47, pp.427-465.

Fama, E.F. and K.R. French (1993), 'Common Risk Factors In the Returns on Stocks and Bonds', Journal of Financial Economics, 33, pp.3-56.

Goergen, M., Khurshed, A. and Mudambi R (2007), The Long Run Performance of UK IPOs: Can it be predicted? Managerial Finance, vol. 33(6), pp. 401-419.

Gregory, A., Harris, R. D. F. and Michou, M. (2001), 'An Analysis of Contrarian Investment Strategies in the UK', Journal of Business Finance \& Accounting, 28, pp.1193-1228.

Gregory, A., and Michou, M. (2007), 'Industry Cost of Capital: UK Evidence', Xfi Working Paper, University of Exeter.

Ikenberry, D., Lakonishok, J. and Vermaelen, T. (1995), 'Market Underreaction to Open Market Share Repurchases', Journal of Financial Economics, 39, pp.181208.

Jaffe, J.F. (1974), 'Special Information and Insider Trading', Journal of Business, 47, pp.410-428.

Levis, M. (1993), 'The Long-Run Performance of Initial Public Offerings: The UK Experience 1980-1988', Financial Management, pp.22, 28-41.

Levis, M. (1995), 'Seasoned Equity Offerings and the Short- and Long-Term Performance of Initial Public Offerings in the UK', European Financial Management, 1, pp.125-146.

Liu, R. Y. (1988), 'Bootstrap Procedure under Some non-i.i.d. models', Annals of Statistics, 16, pp.1696-1708.

Liu, W. and Strong, N. (2008), 'Biases in Decomposing Holding-Period Portfolio Returns', Review of Financial Studies, 21, pp. 2243-2274.

Loughran, T. and Ritter, J.R. (1995), 'The New Issues Puzzle', Journal of Finance, 50, pp.23-51.

Loughran, T. and Ritter, J.R. (2000), 'Uniformly Least Powerful Tests of Market Efficiency', Journal of Financial Economics, 55, pp.361-390.

Lyon, J., Barber, B. and Tsai, C. (1999), 'Improved Methods for Tests of Long-Run Abnormal Stock Returns', Journal of Finance, 54, pp.165-201.

Michou, M., Mouselli, S. and Stark, A.W. (2007), 'Estimating the Fama and French Factors in the UK - An Empirical Review', Manchester Business School Working Paper, University of Manchester.

Mitchell, M.L. and Stafford, E. (2000), 'Managerial Decisions and Long-Term Stock Price Performance', Journal of Business, 73, pp.287-320. 
Ritter, J.R. (1991), 'The Long-Run Performance of Initial Public Offerings', Journal of Finance, 46, pp.3-27.

Schultz, P. (2003), 'Pseudo Market Timing and the Long-Run Underperformance of IPOs', Journal of Finance, 58, pp.483-518.

White, Halbert (1980), 'A Heteroskedastic-Consistent Covariance Matrix Estimator and A Direct Test of Heteroskedasticity', Econometrica, 48, pp.817-838. 
Table 1: IPOs on the UK official list by the year of issue (1975-2004) and the total market capitalisation of all issues at the time of entering the market for each year.

\begin{tabular}{|c|c|c|c|c|c|c|c|c|c|}
\hline $\begin{array}{l}\text { LSPD } \\
\text { Class } \\
\text { \& G8 } \\
\text { Year }\end{array}$ & $\begin{array}{l}\text { Plac- } \\
\text { ing } \\
\text { (53) }\end{array}$ & $\begin{array}{l}\text { Offers } \\
\text { for sale } \\
\text { (54) }\end{array}$ & $\begin{array}{l}\text { Tenders } \\
\text { (55) }\end{array}$ & $\begin{array}{l}\text { Sub- } \\
\text { Scription } \\
\text { (56) }\end{array}$ & $\begin{array}{l}\text { Placing } \\
\text { \& open } \\
\text { Offer } \\
\text { (71) }\end{array}$ & $\begin{array}{l}\text { Placing \& } \\
\text { interme- } \\
\text { diaries } \\
\text { offer (72) }\end{array}$ & $\begin{array}{l}\text { Placing } \\
\& \text { offer } \\
\text { for sale } \\
\text { (73) }\end{array}$ & Total & $\begin{array}{l}\text { Total } \\
\text { Market } \\
\text { Cap. } \\
\text { (£m) }\end{array}$ \\
\hline 1975 & 1 & 1 & & & & & & 2 & 3 \\
\hline 1976 & & 1 & & & & & & 1 & 30 \\
\hline 1977 & 3 & 2 & & & & & & 5 & 43 \\
\hline 1978 & 2 & 8 & & & & & & 10 & 108 \\
\hline 1979 & 2 & 3 & 2 & & & & & 7 & 329 \\
\hline 1980 & 5 & 6 & 1 & 2 & & & & 14 & 131 \\
\hline 1981 & 29 & 13 & 2 & 3 & & & & 47 & 1285 \\
\hline 1982 & 25 & 4 & 3 & 3 & & & & 35 & 3126 \\
\hline 1983 & 55 & 15 & 22 & 2 & & & & 94 & 1846 \\
\hline 1984 & 74 & 26 & 8 & 2 & & & & 110 & 14418 \\
\hline 1985 & 73 & 38 & 8 & 2 & & & & 121 & 3158 \\
\hline 1986 & 86 & 46 & 5 & 2 & & & & 139 & 14071 \\
\hline 1987 & 113 & 21 & & 1 & & & & 135 & 7583 \\
\hline 1988 & 115 & 18 & & 2 & & & 1 & 136 & 7563 \\
\hline 1989 & 73 & 13 & & & & & & 86 & 8035 \\
\hline 1990 & 15 & 13 & & 1 & & & 1 & 30 & 8469 \\
\hline 1991 & 7 & 8 & & 1 & & & 1 & 17 & 9152 \\
\hline 1992 & 26 & 0 & & 1 & & & & 27 & 4648 \\
\hline 1993 & 83 & 1 & & 3 & & 1 & 1 & 89 & 7501 \\
\hline 1994 & 105 & 2 & 1 & & & 6 & 4 & 118 & 13522 \\
\hline 1995 & 58 & 4 & & & & & & 62 & 5406 \\
\hline 1996 & 143 & 5 & & 1 & 1 & 5 & 5 & 160 & 17844 \\
\hline 1997 & 110 & 6 & & & 1 & & 9 & 126 & 17788 \\
\hline 1998 & 66 & 2 & & & & & 2 & 70 & 7624 \\
\hline 1999 & 79 & 5 & & & 3 & & 1 & 88 & 38404 \\
\hline 2000 & 200 & 12 & & & 3 & & 20 & 235 & 29754 \\
\hline 2001 & 88 & 7 & & & 1 & & 10 & 106 & 7754 \\
\hline 2002 & 58 & 3 & & & 2 & & 10 & 73 & 13323 \\
\hline 2003 & 70 & 2 & & & 1 & & 4 & 77 & 7736 \\
\hline 2004 & 269 & 3 & & & 1 & & 6 & 279 & 22596 \\
\hline Total & 2033 & 288 & 52 & 26 & 13 & 12 & 75 & 2499 & 273250 \\
\hline
\end{tabular}

Note: Initial public offerings include offers for sale at fixed price, placement, offers for sale by tenders, and subscriptions. Investment trusts, financial trusts, banks, and over investment firms are excluded. The entire population is based on 2932 issues, 433 are excluded and the sample is 2499 firms is issued during the period 1975-2004. All classifications are based upon the LSPD G8 codes. 


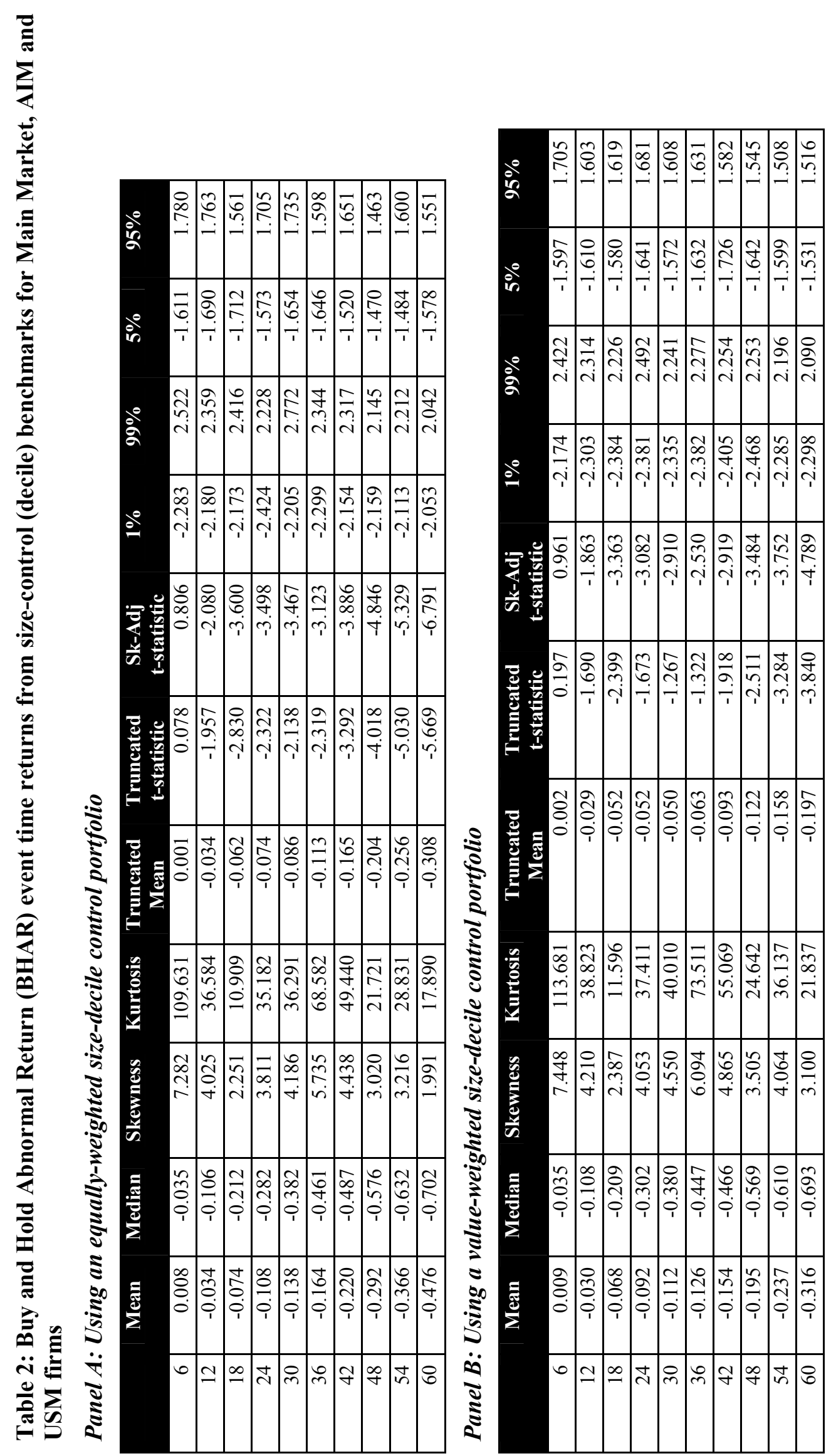




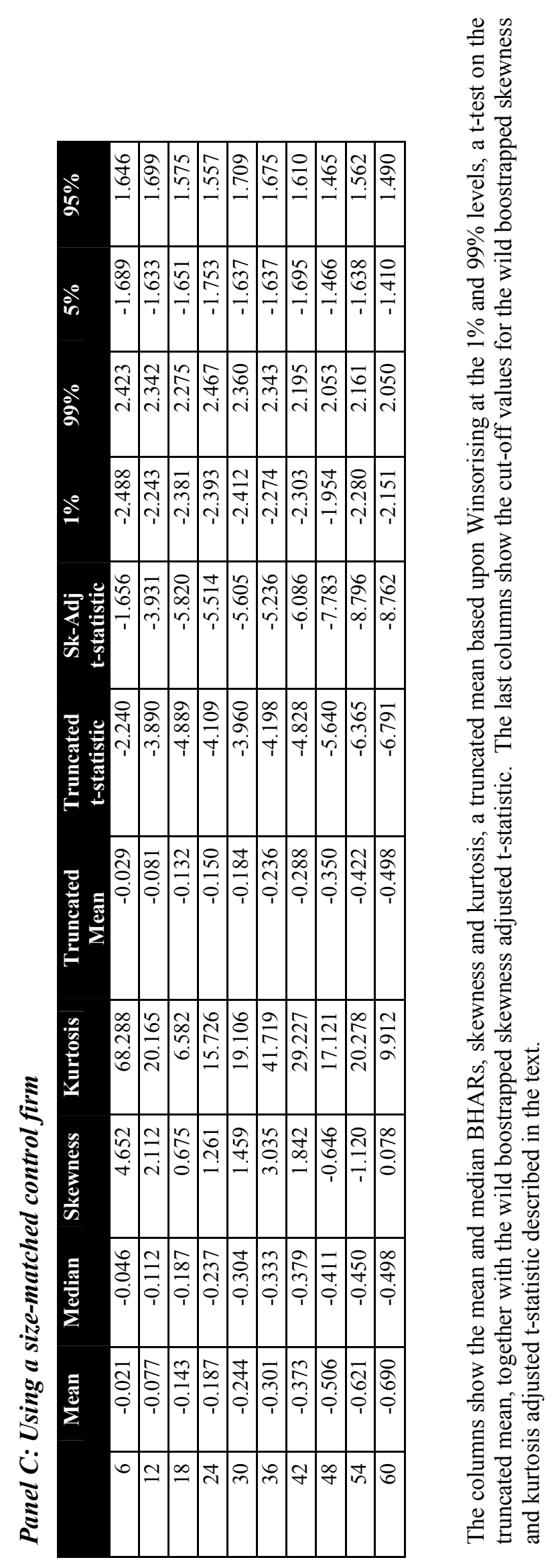




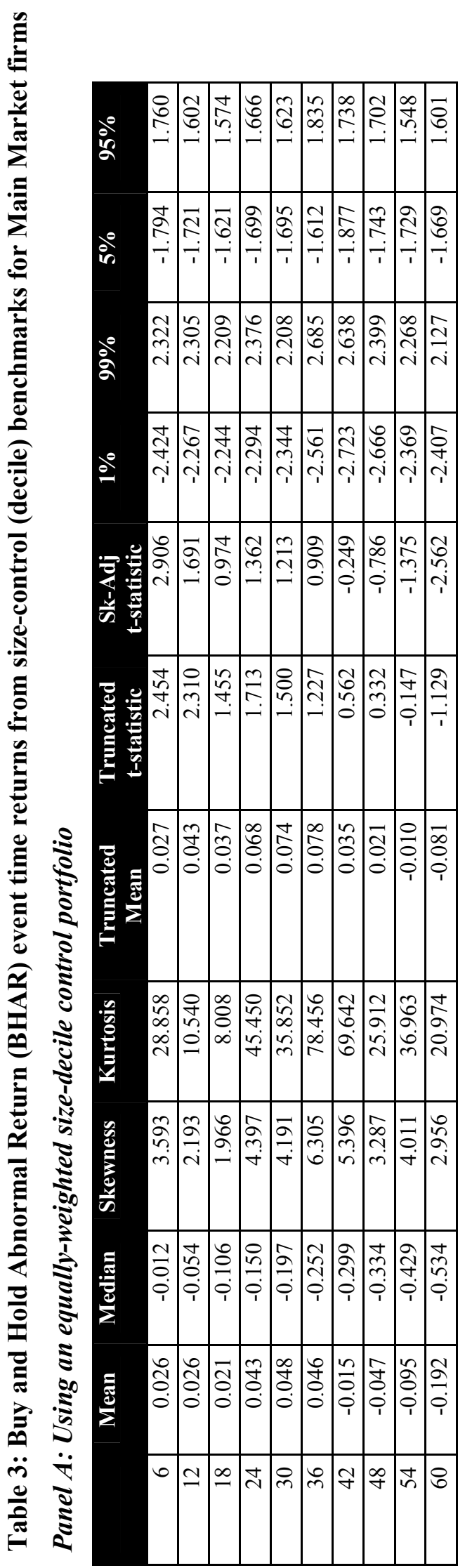

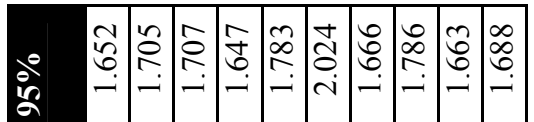

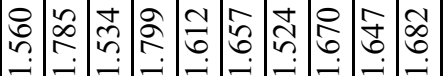

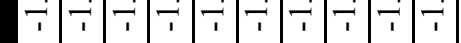

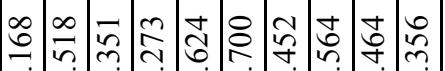

รั

$\stackrel{0}{2}$

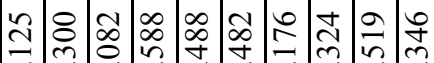

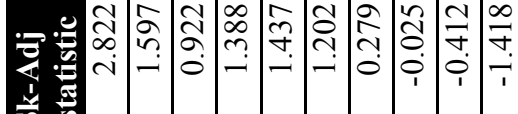

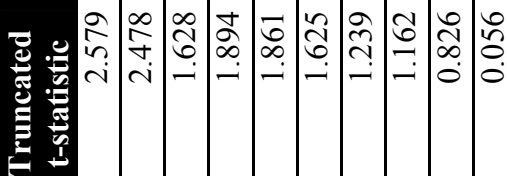

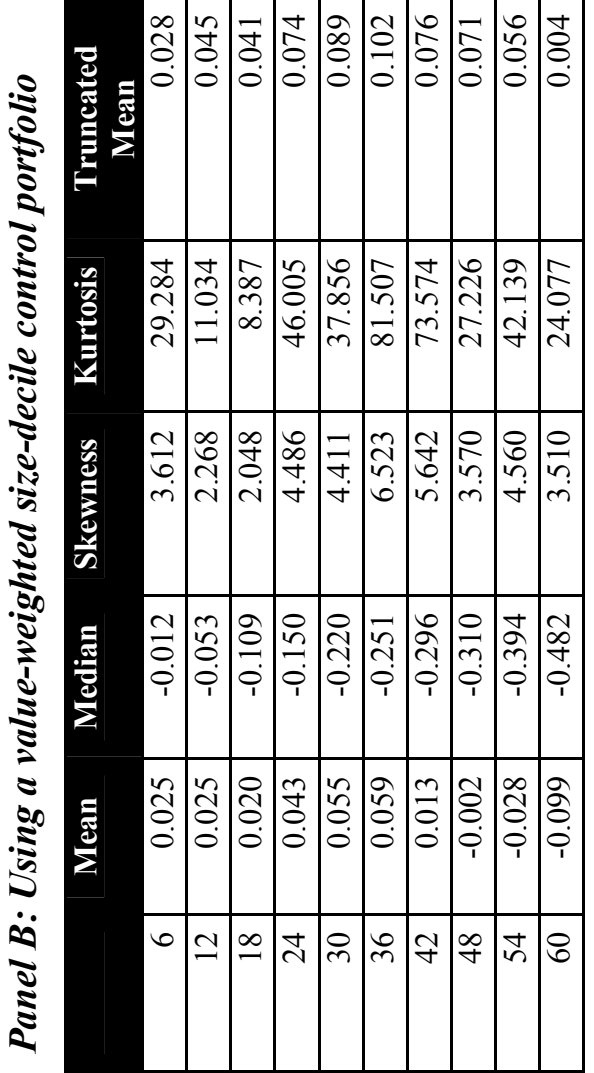




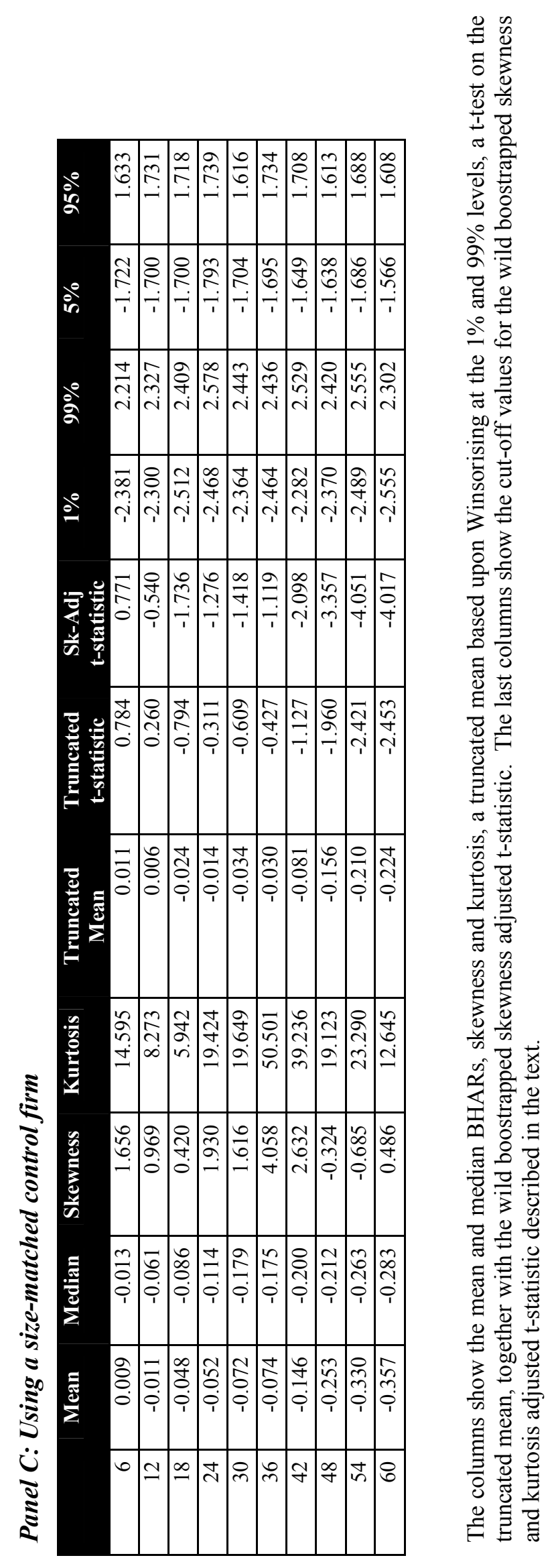




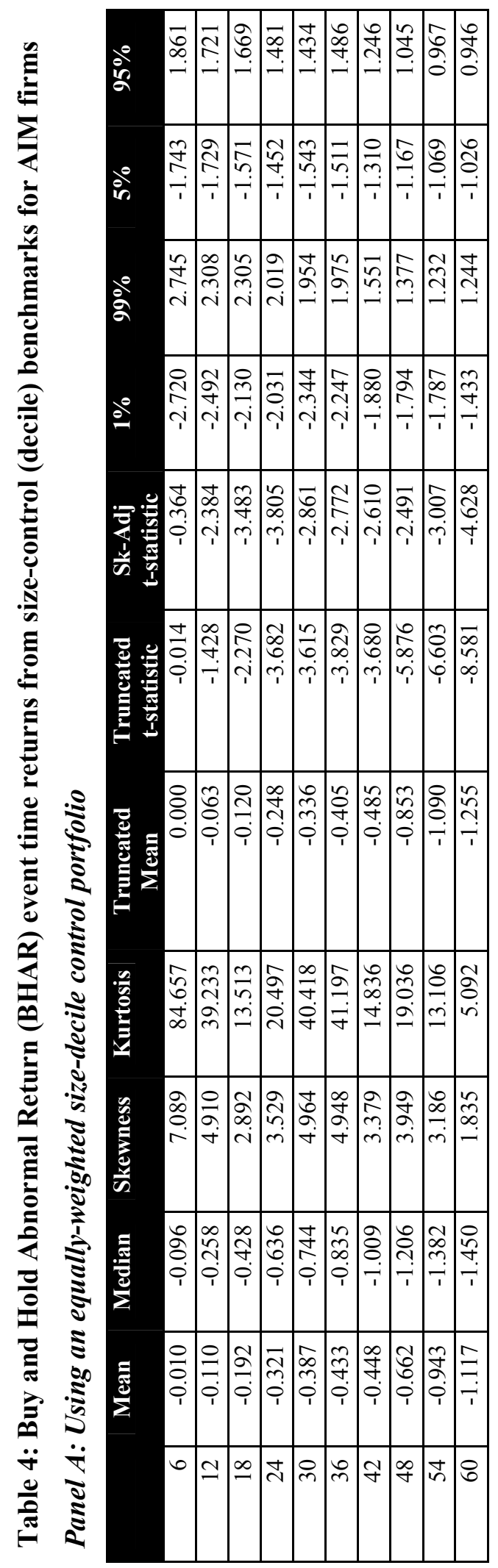

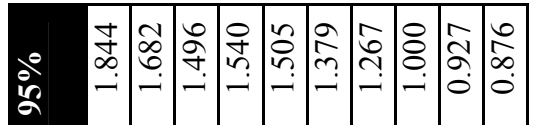

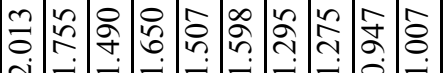




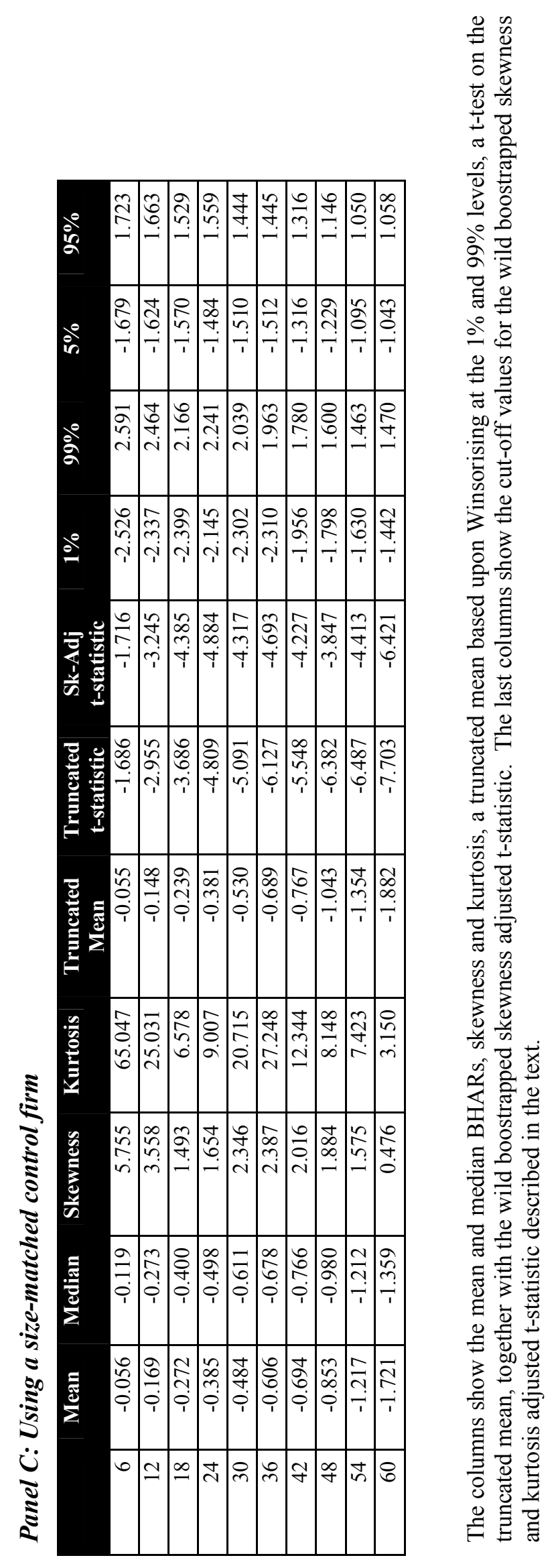



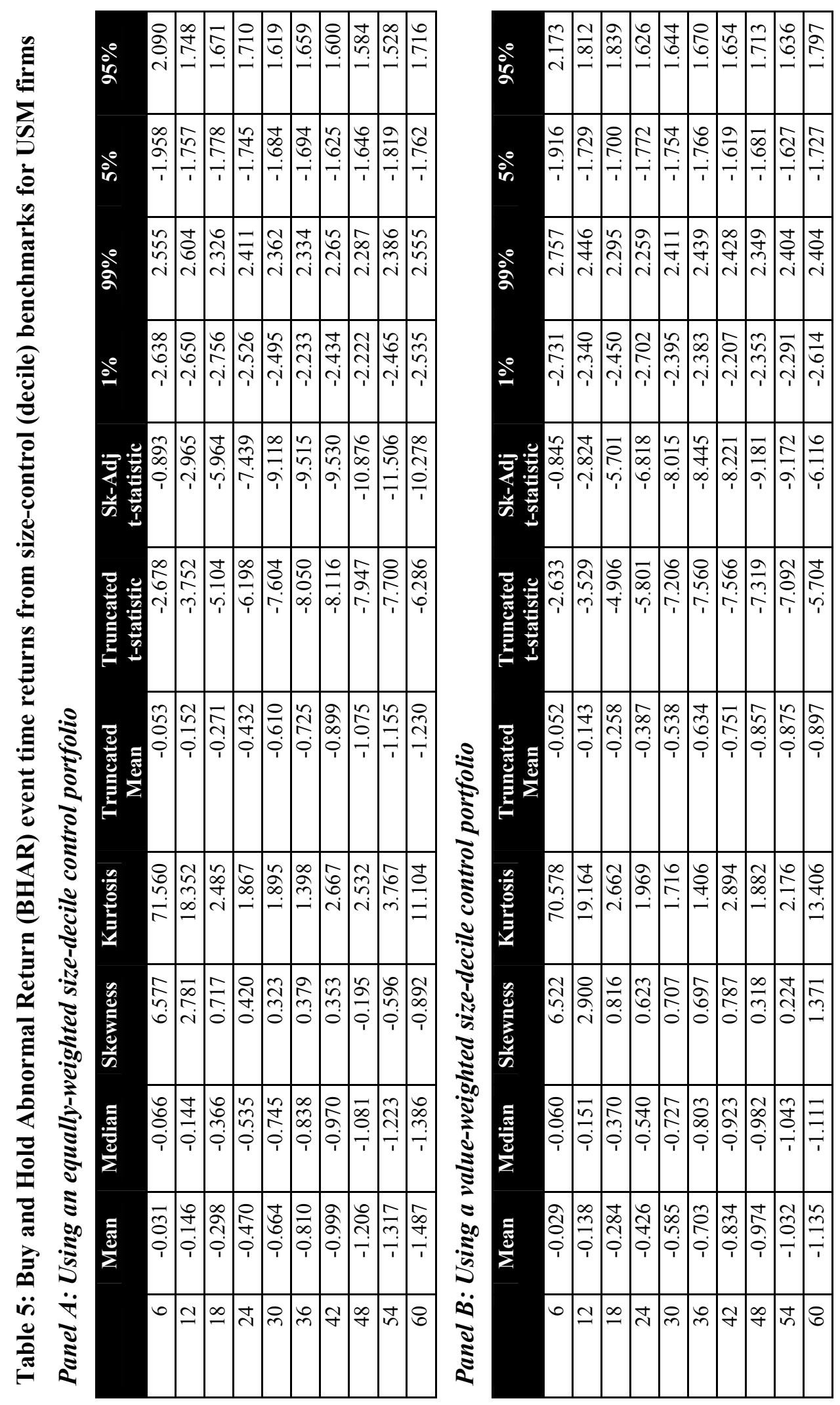

रिन तो ते

m

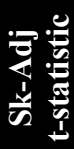

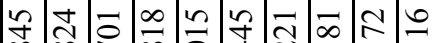

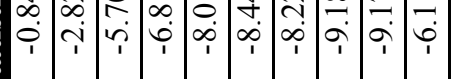

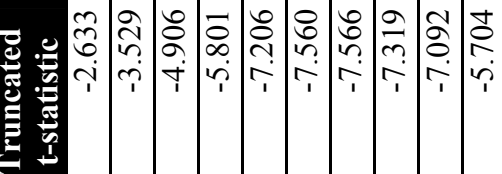

:

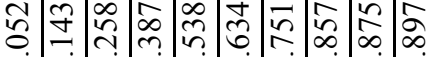

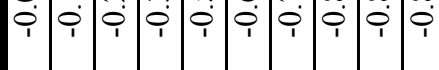

$\stackrel{7}{2}$

:

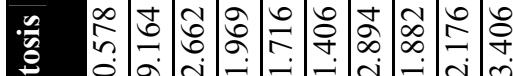

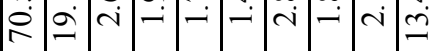

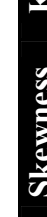

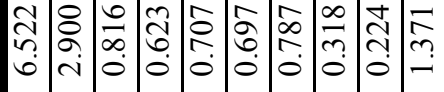

\&̊ำ

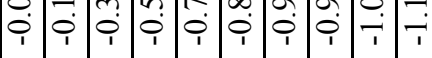

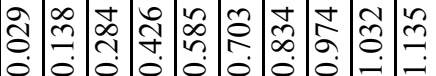

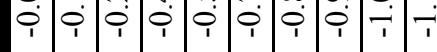

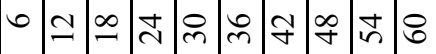




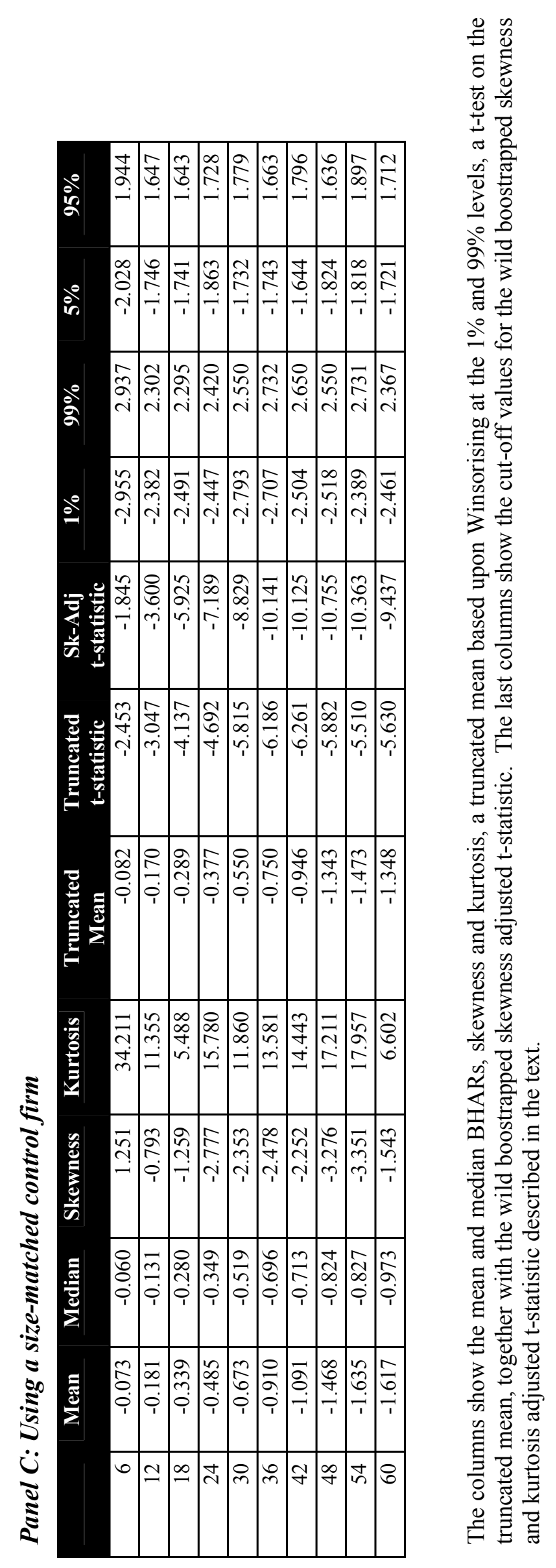


Table 6: Proportions of "bankrupt" firms in the sample of Main Market, AIM and USM IPOs respectively

\begin{tabular}{|l|r|r|}
\hline Market & \multicolumn{1}{l|}{$\begin{array}{l}\text { Percentage } \\
\text { liquidating within 3 } \\
\text { years }\end{array}$} & $\begin{array}{l}\text { Percentage } \\
\text { liquidating } \\
\text { within 5 } \\
\text { years }\end{array}$ \\
\hline Main & $1.2 \%$ & $3.6 \%$ \\
\hline AIM & $4.3 \%$ & $9.5 \%$ \\
\hline USM & $4.3 \%$ & $11.8 \%$ \\
\hline
\end{tabular}

The table shows the cumulative percentage of firms in each market that have delisted for reasons that can be classified as "bankrupt"; this includes firms that enter receivership or are liquidated. 
Table 7: Regression results for the number and value of IPOs.

Panel A: Relative number of IPOs regressions

\begin{tabular}{|l|r|r|r|r|r|r|}
\hline & \multicolumn{3}{|c}{ Full Model } & \multicolumn{3}{c|}{ Restricted Model } \\
\hline Constant & 0.085 & 0.09 & 0.927 & 0.590 & 0.673 & 0.501 \\
\hline$n_{t-1}$ & -0.525 & -2.67 & 0.008 & -0.207 & -1.925 & 0.054 \\
\hline$n_{t-2}$ & 0.027 & 0.23 & 0.821 & & & \\
\hline$n_{t-4}$ & 0.317 & 2.09 & 0.037 & 0.232 & 1.854 & 0.064 \\
\hline$n_{t-5}$ & -0.476 & -3.16 & 0.002 & -0.417 & -3.017 & 0.003 \\
\hline$v_{t-1}$ & 0.409 & 1.00 & 0.319 & & & \\
\hline$v_{t-2}$ & 1.284 & 2.80 & 0.005 & 1.092 & 2.995 & 0.003 \\
\hline$m_{t-1}$ & 110.316 & 4.83 & 0.000 & 110.723 & 4.453 & 0.000 \\
\hline$m_{t-2}$ & 48.909 & 1.56 & 0.120 & & & \\
\hline$s m b_{t-1}$ & 191.258 & 5.02 & 0.000 & 187.678 & 4.918 & 0.000 \\
\hline$s m b_{t-2}$ & 7.071 & 0.14 & 0.891 & & & \\
\hline$h m l_{t-1}$ & 30.813 & 1.19 & 0.233 & & & \\
\hline$h m l_{t-2}$ & 0.087 & 0.00 & 0.998 & & & \\
\hline Trend $(t)$ & 0.259 & 4.64 & 0.000 & 0.225 & 5.089 & 0.000 \\
\hline Adjusted $R^{2}$ & 0.68 & & & & & \\
\hline
\end{tabular}

Panel B: Relative value of IPOs regressions

\begin{tabular}{|l|r|r|r|r|r|r|}
\hline & \multicolumn{3}{|c}{ Full Model } & \multicolumn{3}{c|}{ Restricted Model } \\
\hline Constant & 0.412 & 1.32 & 0.186 & 0.470 & 1.718 & 0.086 \\
\hline$v_{t-1}$ & -0.227 & -0.96 & 0.337 & & & \\
\hline$v_{t-2}$ & 0.267 & 1.78 & 0.074 & 0.333 & 2.344 & 0.019 \\
\hline$v_{t-4}$ & -0.479 & -3.71 & 0.000 & -0.495 & -3.557 & 0.000 \\
\hline$v_{t-5}$ & -0.104 & -0.79 & 0.429 & & & \\
\hline$n_{t-1}$ & 0.116 & 1.57 & 0.117 & & & \\
\hline$n_{t-2}$ & -0.008 & -0.17 & 0.861 & & & \\
\hline$m_{t-1}$ & 27.014 & 3.21 & 0.001 & 23.829 & 2.772 & 0.006 \\
\hline$m_{t-2}$ & -5.468 & -0.44 & 0.662 & & & \\
\hline$s m b_{t-1}$ & -4.726 & -0.33 & 0.741 & & & \\
\hline$s m b_{t-2}$ & -52.764 & -2.92 & 0.004 & -22.722 & -2.802 & 0.005 \\
\hline$h m l_{t-1}$ & 18.045 & 1.37 & 0.170 & & & \\
\hline$h m l_{t-2}$ & 17.721 & 1.75 & 0.080 & 12.609 & 1.637 & 0.102 \\
\hline Trend $(t)$ & 0.022 & 0.90 & 0.366 & 0.031 & 2.244 & 0.025 \\
\hline Adjusted $R^{2}$ & 0.09 & & & 0.35 & & \\
\hline Dependicient & t-statistic & p-value & Coefficient & t-statistic & p-value \\
\hline
\end{tabular}

Dependent variables are the relative number of IPOs $\left(n_{t}\right)$ and the relative value of IPOs $\left(v_{t}\right)$ in Panels A and $\mathrm{B}$ respectively. Independent variables are the lagged values of these variables, together with lagged values for the return on the market $\left(m_{t}\right)$, and the other Fama-French factors $\left(s m b_{t}\right.$ and $\left.h m l_{t}\right)$ 
Table 8: Calendar Time Abnormal Returns (CTAR) from a size-control benchmark

Panel A: Equally weighted CTAR

\begin{tabular}{|c|c|c|c|}
\hline Holding Period & Mean CTAR & t-stat & p-value \\
\hline & \multicolumn{3}{|c|}{ Main, AIM, and USM } \\
\hline 12 & -0.0019 & -0.8570 & 0.3920 \\
\hline 24 & -0.0050 & -3.0483 & 0.0025 \\
\hline 36 & -0.0048 & -3.2683 & 0.0012 \\
\hline 48 & -0.0037 & -2.6180 & 0.0092 \\
\hline 60 & -0.0041 & -3.0077 & 0.0028 \\
\hline
\end{tabular}

Panel B: Value weighted CTAR

\begin{tabular}{|l|r|r|r|}
\hline Holding Period & \multicolumn{2}{c|}{ mean } & p-value \\
\hline 12 & \multicolumn{3}{|c|}{ Main, AIM, and USM } \\
\hline 24 & 0.0051 & 1.5671 & 0.1180 \\
\hline 36 & 0.0034 & 1.2722 & 0.2041 \\
\hline 48 & 0.0028 & 1.2206 & 0.2230 \\
\hline 60 & 0.0027 & 1.3380 & 0.1817 \\
\hline
\end{tabular}


Table 9: Robust (White 1980 Corrected) OLS regressions of IPO Calendar Time Returns on Size-Control Benchmark Return, with sub-market analysis

Panel A: Equally weighted portfolios

\begin{tabular}{|c|c|c|c|}
\hline Holding Period & Alpha & Beta & AdjR2 \\
\hline & \multicolumn{3}{|c|}{ Main, AIM and USM } \\
\hline 12 & -0.003 & 1.111 & 61.7 \\
\hline (t-stat) & -1.562 & 13.153 & \\
\hline 24 & -0.006 & 1.103 & 74.1 \\
\hline (t-stat) & -3.715 & 21.304 & \\
\hline 36 & -0.006 & 1.089 & 77.6 \\
\hline (t-stat) & -3.989 & 23.484 & \\
\hline 48 & -0.005 & 1.093 & 78.8 \\
\hline (t-stat) & -3.450 & 25.684 & \\
\hline 60 & -0.005 & 1.085 & 79.6 \\
\hline \multirow[t]{2}{*}{ (t-stat) } & -3.857 & 26.509 & \\
\hline & \multicolumn{3}{|c|}{ Main } \\
\hline 12 & -0.001 & 1.053 & 60.9 \\
\hline (t-stat) & -0.535 & 19.153 & \\
\hline 24 & -0.002 & 1.102 & 73.9 \\
\hline (t-stat) & -1.475 & 26.979 & \\
\hline 36 & -0.002 & 1.086 & 78.5 \\
\hline (t-stat) & -1.464 & 29.964 & \\
\hline 48 & -0.002 & 1.074 & 79.5 \\
\hline (t-stat) & -1.251 & 31.573 & \\
\hline 60 & -0.003 & 1.061 & 80.6 \\
\hline \multirow[t]{2}{*}{ (t-stat) } & -2.120 & 33.420 & \\
\hline & \multicolumn{3}{|c|}{ AIM } \\
\hline 12 & -0.011 & 1.728 & 62.1 \\
\hline (t-stat) & -2.541 & 5.965 & \\
\hline 24 & -0.014 & 1.500 & 70.9 \\
\hline (t-stat) & -3.285 & 8.906 & \\
\hline 36 & -0.010 & 1.493 & 73.1 \\
\hline (t-stat) & -2.774 & 9.322 & \\
\hline 48 & -0.008 & 1.499 & 76.0 \\
\hline (t-stat) & -2.390 & 11.060 & \\
\hline 60 & -0.007 & 1.526 & 75.0 \\
\hline \multirow[t]{2}{*}{ (t-stat) } & -2.134 & 9.789 & \\
\hline & \multicolumn{3}{|c|}{ USM } \\
\hline 12 & -0.010 & 0.882 & 17.7 \\
\hline (t-stat) & -1.310 & 7.558 & \\
\hline 24 & -0.018 & 0.892 & 10.6 \\
\hline (t-stat) & -1.718 & 6.432 & \\
\hline 36 & -0.011 & 0.837 & 11.5 \\
\hline (t-stat) & -1.296 & 6.724 & \\
\hline 48 & -0.008 & 0.991 & 27.5 \\
\hline (t-stat) & -1.510 & 11.778 & \\
\hline 60 & -0.009 & 1.000 & 41.2 \\
\hline (t-stat) & -2.201 & 17.121 & \\
\hline
\end{tabular}


Panel B: Value weighted portfolios

\begin{tabular}{|c|c|c|c|}
\hline Holding Period & Alpha & Beta & AdjR2 \\
\hline & \multicolumn{3}{|c|}{ Main, AIM and USM } \\
\hline 12 & 0.004 & 1.108 & 43.1 \\
\hline (t-stat) & 1.407 & 14.350 & \\
\hline 24 & 0.002 & 1.209 & 55.7 \\
\hline (t-stat) & 0.719 & 17.737 & \\
\hline 36 & 0.001 & 1.168 & 61.1 \\
\hline (t-stat) & 0.695 & 21.588 & \\
\hline 48 & 0.002 & 1.155 & 65.8 \\
\hline (t-stat) & 0.802 & 23.913 & \\
\hline 60 & 0.001 & 1.139 & 68.1 \\
\hline (t-stat) & 0.605 & 25.344 & \\
\hline & \multicolumn{3}{|c|}{ Main } \\
\hline 12 & 0.005 & 1.116 & 44.8 \\
\hline (t-stat) & 1.524 & 15.512 & \\
\hline 24 & 0.004 & 1.226 & 56.5 \\
\hline (t-stat) & 1.423 & 18.097 & \\
\hline 36 & 0.003 & 1.172 & 61.4 \\
\hline (t-stat) & 1.254 & 21.501 & \\
\hline 48 & 0.003 & 1.146 & 66.4 \\
\hline (t-stat) & 1.371 & 24.194 & \\
\hline 60 & 0.002 & 1.130 & 68.5 \\
\hline (t-stat) & 1.110 & 25.691 & \\
\hline & \multicolumn{3}{|c|}{ AIM } \\
\hline 12 & 0.018 & 2.260 & 25.7 \\
\hline (t-stat) & 1.551 & 2.934 & \\
\hline 24 & 0.001 & 2.346 & 35.1 \\
\hline (t-stat) & 0.061 & 3.683 & \\
\hline 36 & -0.002 & 2.330 & 45.4 \\
\hline (t-stat) & -0.239 & 4.665 & \\
\hline 48 & -0.001 & 2.228 & 50.4 \\
\hline (t-stat) & -0.127 & 5.645 & \\
\hline 60 & 0.000 & 2.234 & 50.9 \\
\hline (t-stat) & -0.071 & 5.431 & \\
\hline & \multicolumn{3}{|c|}{ USM } \\
\hline 12 & -0.008 & 1.012 & 18.9 \\
\hline (t-stat) & -1.015 & 7.525 & \\
\hline 24 & -0.026 & 1.093 & 11.2 \\
\hline (t-stat) & -2.233 & 7.310 & \\
\hline 36 & -0.012 & 1.081 & 13.5 \\
\hline (t-stat) & -1.223 & 7.779 & \\
\hline 48 & -0.009 & 1.186 & 25.0 \\
\hline (t-stat) & -1.236 & 11.977 & \\
\hline 60 & -0.011 & 1.147 & 37.9 \\
\hline (t-stat) & -2.148 & 13.406 & \\
\hline
\end{tabular}


Table 10: GLS regressions of IPO Calendar Time Returns on Size-Control Benchmark Return, with sub-market analysis

\section{Panel A: Equally weightedpPortfolios}

\begin{tabular}{|c|c|c|c|}
\hline Holding Period & Alpha & Beta & AdjR2 \\
\hline & \multicolumn{3}{|c|}{ Main, AIM and USM } \\
\hline 12 & -0.006 & 1.198 & 68.5 \\
\hline (t-stat) & -3.020 & 13.461 & \\
\hline 24 & -0.008 & 1.161 & 79.0 \\
\hline (t-stat) & -5.098 & 20.811 & \\
\hline 36 & -0.007 & 1.163 & 83.4 \\
\hline (t-stat) & -4.994 & 22.273 & \\
\hline 48 & -0.005 & 1.173 & 85.4 \\
\hline (t-stat) & -4.126 & 24.698 & \\
\hline 60 & -0.006 & 1.168 & 87.1 \\
\hline (t-stat) & -4.947 & 26.391 & \\
\hline & \multicolumn{3}{|c|}{ Main } \\
\hline 12 & -0.002 & 1.105 & 72.0 \\
\hline (t-stat) & -1.004 & 22.255 & \\
\hline 24 & -0.003 & 1.129 & 79.9 \\
\hline (t-stat) & -2.300 & 27.562 & \\
\hline 36 & -0.002 & 1.125 & 85.9 \\
\hline (t-stat) & -2.059 & 33.912 & \\
\hline 48 & -0.002 & 1.126 & 87.9 \\
\hline (t-stat) & -1.709 & 38.105 & \\
\hline 60 & -0.003 & 1.120 & 89.9 \\
\hline \multirow[t]{2}{*}{ (t-stat) } & -3.199 & 43.568 & \\
\hline & \multicolumn{3}{|c|}{ AIM } \\
\hline 12 & -0.011 & 1.718 & 62.4 \\
\hline (t-stat) & -2.649 & 6.081 & \\
\hline 24 & -0.015 & 1.487 & 71.8 \\
\hline (t-stat) & -3.825 & 9.375 & \\
\hline 36 & -0.010 & 1.492 & 73.2 \\
\hline (t-stat) & -2.856 & 9.365 & \\
\hline 48 & -0.008 & 1.499 & 76.9 \\
\hline (t-stat) & -2.671 & 11.235 & \\
\hline 60 & -0.008 & 1.522 & 76.2 \\
\hline \multirow[t]{2}{*}{ (t-stat) } & -2.538 & 10.117 & \\
\hline & \multicolumn{3}{|c|}{ USM } \\
\hline 12 & -0.012 & 0.981 & 51.7 \\
\hline (t-stat) & -3.563 & 12.959 & \\
\hline 24 & -0.014 & 0.975 & 57.5 \\
\hline (t-stat) & -5.595 & 19.286 & \\
\hline 36 & -0.014 & 0.928 & 42.2 \\
\hline (t-stat) & -4.987 & 18.174 & \\
\hline 48 & -0.012 & 1.000 & 45.4 \\
\hline (t-stat) & -3.547 & 17.908 & \\
\hline 60 & -0.011 & 1.003 & 50.4 \\
\hline (t-stat) & -3.600 & 20.032 & \\
\hline
\end{tabular}


Panel B: Value weighted portfolios

\begin{tabular}{|c|c|c|c|}
\hline Holding Period & Alpha & Beta & AdjR2 \\
\hline & \multicolumn{3}{|c|}{ Main, AIM and USM } \\
\hline 12 & 0.002 & 1.202 & 45.1 \\
\hline (t-stat) & 0.685 & 13.887 & \\
\hline 24 & 0.001 & 1.282 & 57.4 \\
\hline (t-stat) & 0.287 & 17.482 & \\
\hline 36 & 0.001 & 1.247 & 63.3 \\
\hline (t-stat) & 0.268 & 21.778 & \\
\hline 48 & 0.001 & 1.221 & 68.2 \\
\hline (t-stat) & 0.439 & 25.194 & \\
\hline 60 & 0.000 & 1.209 & 71.1 \\
\hline (t-stat) & 0.090 & 27.559 & \\
\hline & \multicolumn{3}{|c|}{ Main } \\
\hline 12 & 0.004 & 1.198 & 48.1 \\
\hline (t-stat) & 1.203 & 14.973 & \\
\hline 24 & 0.003 & 1.277 & 58.5 \\
\hline (t-stat) & 1.054 & 18.117 & \\
\hline 36 & 0.002 & 1.234 & 64.3 \\
\hline (t-stat) & 0.889 & 22.401 & \\
\hline 48 & 0.002 & 1.211 & 70.1 \\
\hline (t-stat) & 0.910 & 26.449 & \\
\hline 60 & 0.001 & 1.189 & 72.1 \\
\hline (t-stat) & 0.631 & 29.042 & \\
\hline & \multicolumn{3}{|c|}{ AIM } \\
\hline 12 & 0.014 & 2.157 & 26.3 \\
\hline (t-stat) & 1.262 & 3.230 & \\
\hline 24 & 0.001 & 2.372 & 35.0 \\
\hline (t-stat) & 0.150 & 3.622 & \\
\hline 36 & 0.000 & 2.354 & 44.7 \\
\hline (t-stat) & 0.065 & 4.570 & \\
\hline 48 & 0.001 & 2.226 & 49.4 \\
\hline (t-stat) & 0.104 & 5.605 & \\
\hline 60 & 0.000 & 2.237 & 50.4 \\
\hline (t-stat) & 0.032 & 5.391 & \\
\hline & \multicolumn{3}{|c|}{ USM } \\
\hline 12 & -0.011 & 1.106 & 42.4 \\
\hline (t-stat) & -2.389 & 10.340 & \\
\hline 24 & -0.020 & 1.172 & 41.8 \\
\hline (t-stat) & -4.780 & 14.358 & \\
\hline 36 & -0.016 & 1.120 & 31.3 \\
\hline (t-stat) & -3.445 & 14.078 & \\
\hline 48 & -0.008 & 1.185 & 23.4 \\
\hline (t-stat) & -1.052 & 11.394 & \\
\hline 60 & -0.011 & 1.147 & 37.7 \\
\hline (t-stat) & -2.099 & 13.343 & \\
\hline
\end{tabular}


Table 11: IPO firms by relative size.

Panel A: Break points and summary statistics of relative size.

\begin{tabular}{|c|c|c|c|c|c|}
\hline & Q1 & Q2 & Q3 & Q4 & Q5 \\
\hline Definition & $<0.0005$ & $\begin{aligned}>= & 0.0005 \\
& <0.001\end{aligned}$ & $\begin{aligned}>= & 0.001 \\
& <0.01\end{aligned}$ & $\begin{aligned}> & =0.01 \\
& <0.05\end{aligned}$ & $>=0.05$ \\
\hline $\begin{array}{l}\text { Proportion of } \\
\text { total }\end{array}$ & $13.5 \%$ & $10.1 \%$ & $56.7 \%$ & $16.1 \%$ & $3.6 \%$ \\
\hline Mean (\%) & 0.000268 & 0.000736 & 0.003886 & 0.019744 & 0.147976 \\
\hline Median (\%) & 0.000269 & 0.000704 & 0.003179 & 0.016316 & 0.083013 \\
\hline $\operatorname{Min}(\%)$ & 0.000017 & 0.000506 & 0.001011 & 0.010000 & 0.050723 \\
\hline $\operatorname{Max}(\%)$ & 0.000496 & 0.000991 & 0.009989 & 0.049732 & 0.807861 \\
\hline
\end{tabular}

Panel B: Regression results of performance on size and market segments.

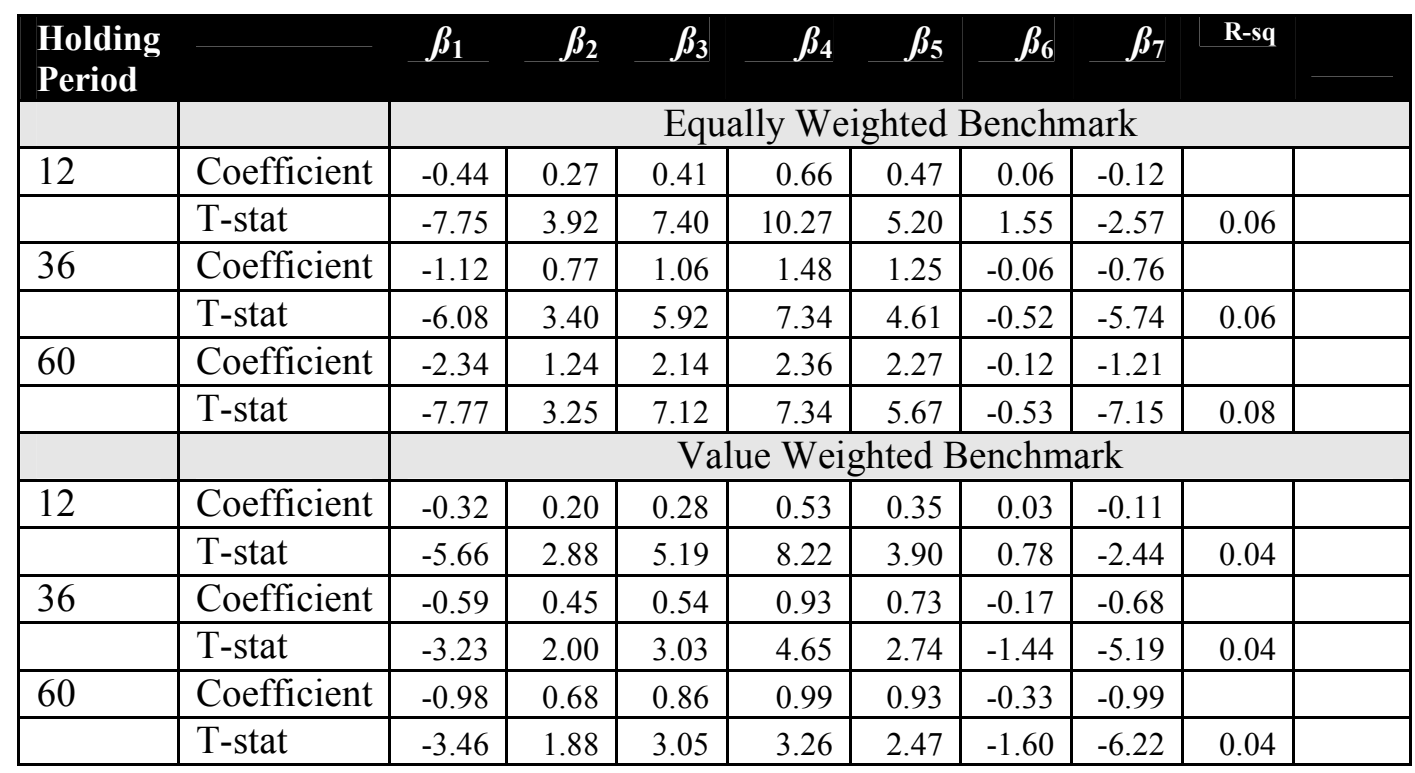

Break-points were obtained as follows. We first calculate the relative value of a given IPO by dividing its market value at issue by the total market capitalisation of that year. This will give us the size of the IPO relative to its current market. We then divide IPOs into five quintiles. The smallest quintile (Q1) includes IPOs whose value is less than $0.0005 \%$ of the total market capitalisation (at the time of issue), while the largest quintile (Q5) includes IPOs whose value is greater than or equal to $0.05 \%$ of the total market capitalisation.

Using these breakpoints, we then run the following regression, with BHARs from equally weighted and value weighted benchmarks respectively:

$$
B H A R=\beta_{1}+\beta_{2} D 2+\beta_{3} D 3+\beta_{4} D 4+\beta_{5} D 5+\beta_{6} A I M+\beta_{7} U S M
$$

Where D2 to D5 are dummies for size. For example, D3 equals 1 for firms belonging to the third quintile and zero otherwise. The intercept accounts for the lowest size. AIM and USM are dummies for USM and AIM companies respectively. 
Appendix 1. LSPD codes and descriptions of type of delisting.

\begin{tabular}{|c|c|}
\hline Code & Description \\
\hline 5 & Acquisition/takeover/merger \\
\hline 6 & $\begin{array}{l}\text { Suspension/cancellation with shares acquired later. Meanwhile, may be } \\
\text { traded under rule 163(2) }\end{array}$ \\
\hline 7 & Liquidation (usually valueless, but there may be liquidation payments) \\
\hline 8 & $\begin{array}{l}\text { Quotation cancelled (maybe suspended initially) as company becomes a } \\
\text { private company, or there is insufficient trading in the shares. Dealings } \\
\text { continue under rule } 163(2) \text { or (3) }\end{array}$ \\
\hline 9 & As for 8 , but no dealings under rule 163 \\
\hline 10 & $\begin{array}{l}\text { Quotation suspended - if suspended for more than three years, this may lead } \\
\text { to automatic cancellation }\end{array}$ \\
\hline 11 & Voluntary liquidation, where value remains and was / is being distributed \\
\hline 12 & Changed to foreign registration \\
\hline 13 & $\begin{array}{l}\text { Quotation cancelled for reason unknown. Dealings continue under rule } \\
163(2) \text { or (3) }\end{array}$ \\
\hline 14 & As for 13 , but no dealings under rule 163 \\
\hline 15 & Converted into an alternative security for the same company \\
\hline 16 & Receiver appointed/liquidation. Probably valueless, but not yet certain \\
\hline 17 & Unitisation of an investment or financial trust \\
\hline 18 & Nationalisation \\
\hline 19 & Enfranchisement \\
\hline 20 & In Administration/Administrative receivership \\
\hline 21 & Cancelled and assumed valueless \\
\hline
\end{tabular}

Source: LSPD manual handbook 2006. This table represents the type of death (G10) in the LSPD manual, which indicates to the reason why the security ceased to be in the SEDOL. 